\title{
Embargando rentas, desembargando voluntades. La suspensión de libranzas de 1509 y el régimen fiscal de Castilla ${ }^{1}$
}

\author{
David Alonso García ${ }^{2}$
}

Recibido: 15 de enero de 2016 / Aceptado: 22 de abril de 2016

Resumen. La historiografía de los últimos años viene demostrando que muchos de los elementos que caracterizaron el sistema fiscal-financiero de los Austrias comenzaron a formarse con anterioridad. Cuestiones tan importantes como los encabezamientos, el recurso a los juros o la presencia de un mercado financiero en los sistemas de arrendamiento y créditos bajo diversas modalidades, pasaron a ser parte de la realidad castellana desde aquellos instantes. En esta línea, también hubo algún acontecimiento que puede ser tomado como precedente de las célebres "bancarrotas" y que, en definitiva, demuestra que ya en aquellos momentos existía un precario equilibrio en torno a los sistemas de crédito que nutrían a la hacienda real. El presente trabajo da a conocer uno de aquellos episodios a partir del análisis de una suspensión de libranzas ordenada por Fernando el Católico en febrero de 1509. La presente investigación parte de la consulta de fuentes inéditas procedentes, principalmente, del Archivo General de Simancas.

Palabras clave: Deuda flotante; suspensión de pagos; Fernando el Católico; libranzas.

\section{[en] Suffling Taxes, unloading Wills. The Failure of 1509 and the Castile Tax System}

\begin{abstract}
Current scholars are showing that fiscal-financial system of the Austrias was shaping since ca. 1490. Important tasks like "headings", bonds (juros) or the participation of a financial groups in loans or tax farming took part of the common reality of Castilians from this moment. In this hand, there was also some events that can be taken as precedents of the famous "bankruptcies" and, in short, these episodes of financial crises show that there was a precarious balance around the credit systems that nourished the real estate before the Habsburg rule. This article focuses on a suspension of libranzas ordered by Fernando el Católico in February of 1509. Unpublished sources coming mainly from the Archive of Simancas has been used in order to elaborate the study.
\end{abstract}

Keywords: Short-Term Debt; Default; Ferdinand the Catholic; Payments.

Sumario. 1. El mundo de la hacienda a principios del siglo XVI. 2. El decreto de suspensión de libranzas de 1509. 3. Las cartas particulares de desembargo. 4. Las consecuencias del embargo. Estado de las rentas en 1511. 5. Reflexiones finales. 6. Apéndice I: Decreto de suspensión de libranzas. 7. Apéndice II: Excepciones particulares al embargo general de rentas.

\footnotetext{
1 Proyecto de investigación: "La jerarquización urbana: villas y ciudades en Castilla (1400-1561)". Ministerio de Ciencia e Innovación. HAR2013-44014-P. Agradezco las sugerencias recibidas por parte de los evaluadores anónimos.

2 Universidad Complutense. Departamento de Historia Moderna y de Historia Contemporánea E-mail: davalonso@ghis.ucm.es
} 
Cómo citar: Alonso García, D. (2017): "Embargando rentas, desembargando voluntades. La suspensión de libranzas de 1509 y el régimen fiscal de Castilla", en Cuadernos de Historia Moderna 42.2, 441-468.

El estudio de las suspensiones de pagos por parte de la Monarquía Hispánica constituye uno de los focos de interés más importantes en cualquier análisis sobre la hacienda castellana de los siglos XVI y XVII ${ }^{3}$. Los últimos años han resultado pródigos en nuevas interpretaciones sobre el fenómeno del crédito y la deuda de los siglos modernos, llamando incluso la atención de relevantes economistas ${ }^{4}$. En un conocido estudio, los profesores F. Comín y M. Hernández han catalogado diferentes estadios de crisis económica desde el siglo $\mathrm{XV}^{5}$. En su taxonomía se incluyen las suspensiones de pago de diferente naturaleza, reestructuraciones de la deuda, impuestos sobre los títulos, etc. Este elenco demuestra que los episodios de "crisis" en materia hacendística no sólo cabe identificarlos con las "bancarrotas" sino con otras medidas que genéricamente permiten hablar del "problema de la deuda" sin que necesariamente se produjese el clásico mecanismo de reconversión de deuda flotante a consolidada que estaba detrás de los decretos de suspensión de pagos de época de los Austrias.

Esta ampliación de horizontes o categorías permite retrotraer el análisis de las suspensiones a épocas anteriores. Así, con la presente investigación pretendemos ofrecer alguna noticia sobre una suspensión de libranzas dictada en 1509, que de algún modo puede ser interpretada como nexo de unión entre la época de los Trastámara y de los Austrias ${ }^{6}$. Dado que apenas contamos con estudios sobre esta suspensión (parcial) de pagos, pensamos que el presente trabajo añade otra muesca más a los episodios de crisis de la deuda que vienen jalonando la historia de España desde aquellos momentos.

\section{El mundo de la hacienda a principios del siglo XVI}

Los comienzos del siglo XVI fueron un momento particularmente interesante en la historia de la hacienda castellana en tanto se confirmó el papel predominante de los grupos financieros en los mecanismos de financiación de la monarquía. Una de las consecuencias de esta dinámica fue el constante riesgo de atrasos en los cobros o directamente de suspensiones. Ya en 1504, por ejemplo, la contabilidad oficial demuestra que las libranzas no podían ser sustentadas sólo con rentas ordinarias? ${ }^{7}$. En 1516 Carlos V decretó una suspensión de las libranzas extraordinarias, si bien esta medida cabe interpretarla principalmente en clave política ${ }^{8}$.

3 Remitimos sobre ello al magnífico artículo de J. M. Escribano y Alejandro García Montón incluido en el presente monográfico.

4 Reinhart, C. M y Rogoff, K. S.: Esta vez es distinto. Ocho siglos de necedad financiera, Madrid, Fondo de Cultura Económica, 2001, pp. 96-97 y 114-116.

5 Comín, F y Hernández, M.: “Apuros, ahogos, arreglos y bancarrotas. Las crisis de la deuda pública, 15042012”, en Comín, F. y Hernández, M. (eds.): Crisis económicas en España, 1300-2012. Lecciones de la Historia, Madrid, Alianza Editorial, 2013, pp. 169-201.

6 A modo de ejemplo, Comín, F.: Las crisis de la deuda soberana en España (1500-2015), Madrid, Los Libros de la Catarata, 2016.

7 Ladero Quesada, M. A.: La Hacienda Real de Castilla 1369-1504. Estudios y documentos, Madrid, Real Academia de la Historia, 2009, p. 657.

8 De Carlos Morales, C. J.: Carlos V y el crédito de Castilla. El tesorero general Francisco de Vargas y la 
Para entender estas situaciones de riesgo o quiebra resulta imprescindible integrar su análisis en los esquemas políticos e incluso culturales en los que se movía la hacienda castellana de aquellos momentos. El sistema fiscal de principios del siglo XVI se caracterizaba por dos elementos esenciales para entender los mecanismos de pago. En primer lugar, como ya hemos apuntado, el concurso sistemático a agentes financieros que hacían las veces de intermediarios entre la hacienda real y el contribuyente, en algún caso la banca internacional y las ciudades, siempre protagonistas en el régimen de recaudación de rentas ${ }^{9}$. El concurso de estos agentes, que en términos historiográficos aparecen tras el difuso calificativo de "poder financiero", se realizaba mediante arrendamientos de rentas y créditos a corto plazo que en las fuentes se les denominan "obligaciones a guardas" en tanto el destino fundamental de este capital no era otro que el ejército. Obsérvese que el término "obligaciones a guardas" implicaba la movilización de cantidades superiores a los 100 millones de maravedíes anuales a recuperar sobre libranzas específicas y garantizados en no pocas ocasiones por tesorerías de rentas encabezadas ${ }^{10}$.

En segundo lugar, la participación de agentes privados resulta relevante ya que sólo así se entiende que el sistema funcionaba como un circuito de retroalimentación financiera donde las aportaciones de capital -insistimos, constantes y como parte del sistema de financiación de la corona- dependían de la capacidad para nutrirlo mediante fuentes de ingreso de diferente naturaleza. El problema o la contradicción en este punto deriva de la necesidad constante de mantener un sistema de crédito ordinario en contextos de crisis subsistencias o pestes que amenazaban con cortar los canales de recaudación y de gestión de las compañías que se encontraban al frente de la cobranza de impuestos. A este elemento hay que sumar otro de capital importancia ocurrida en los años previos a la suspensión aquí analizada: la crisis dinástica de 1504-1507 no se hizo sobre algo parecido a una división del territorio sino desde la convivencia de una doble administración que entendía sobre las mismas rentas y partidos fiscales. La traducción inmediata de esta situación hay que buscarla en la existencia de tres contadurías o grupos con capacidad legal para expedir documentación (hojas de cargo, libranzas, recaudos, manejo de contabilidad, etc.), dirigida una de ellas por alguien tan cercano a Felipe I como fue don Juan Manuel. Dicho de otro modo, sobre un mismo asunto se podía encontrar diferentes variantes o documentos que facultaban para la cobranza de rentas o libranzas, con las consiguientes dudas de legalidad, supuestas o inventadas ${ }^{11}$. El incremento nominal de los precios de rentas, que en apenas diez años fue de un $11 \%^{12}$ no hay que tomarlo como sinónimo de me-

Hacienda Real entre 1516 y 1524, Madrid, Sociedad Estatal para la Conmemoración de los Centenarios de Felipe II y Carlos V, 2000, p. 23. Alonso GARCíA, D.: El erario del reino. Fiscalidad en Castilla a principios de la Edad Moderna, 1503-1525, Valladolid, Junta de Castilla y León, 2007, pp. 282-284.

$9 \quad$ Véase, entre otros, el análisis de redes propuesto por ORTEGo Rico, P.: Poder financiero y gestión tributaria en Castilla: los agentes fiscales en Toledo y su reino (1429-1504), Madrid, Instituto de Estudios Fiscales, 2015.

10 Las últimas publicaciones al respecto son OrTEGo Rico, P.: "La financiación de las guardas reales durante el reinado de los Reyes Católicos: crédito y finanzas a través de la actividad del tesorero Ruy López de Toledo", en Martínez Ruiz, E., Cantera Montenegro, J. y Pazzis Pi Corrales, M. de (dirs.): La Organización de los Ejércitos, Madrid, Cátedra Extraordinaria Complutense de Historia Militar, 2016, Vol. I, pp. 428-473 y Alonso GarcíA, D.: "El alimento de Marte. Proveedores de ejército a principios de la Edad Moderna", en ibidem, pp. 501-537.

11 Sobre la crisis de 1504-1508 remitimos a GonZÁLEZ CERA, Á.: "Granada frente a la crisis financiera castellana, 1504-1508", Histoire Urbaine, no 33 (2012), pp. 41-61.

12 Alonso García, op. cit. (nota 8), p. 25. 
jora de la capacidad fiscal de la corona. A lo largo de las dos primeras décadas del siglo XVI fueron constantes las quejas de los arrendatarios de rentas por no cobrar, acompañadas, por otro lado, de la pesadumbre de muchos juristas o beneficiarios de libranzas que encontraban enormes dificultades para hacer valer su título o su derecho a cobro.

Hay que recordar en este punto cómo funcionaba el sistema de pago de libranzas. La administración emitía el correspondiente recibo para su cobro, señalado sobre un determinado partido y unas determinadas rentas, fuera sobre un ejercicio fiscal presente o pasado ${ }^{13}$. Estas cartas u órdenes se emitían en función de los libros de la Contaduría y de la nómina general, que curiosamente tendía a confeccionarse a finales del ejercicio o al año siguiente. Por tanto, el abono de las libranzas se asignaba a rentas que podían haberse cobrado -o no- y en no pocas ocasiones se consignaba sobre años ya cumplidos (con retraso, por tanto), creando enormes dificultades en su gestión y control por parte de los organismos rectores de la hacienda ${ }^{14}$. Los financieros o los receptores de las ciudades debían aceptarlas en cuanto el particular presentase el documento y, una vez satisfecho su importe, pasaban a señalarlo en las datas presentadas a la Contaduría Mayor de Cuentas.

No debe extrañar, por consiguiente, que el sistema ofreciese numerosas dudas en cuanto a su funcionamiento. En primer lugar, porque las libranzas debían abonarse una vez satisfecho el situado, como consta en las nóminas generales que elaboraba la Contaduría año tras año ${ }^{15}$. Al no existir una vinculación directa entre cuantías efectivamente ingresadas y la expedición de libranzas, siempre cabía la duda acerca de si el financiero de turno estaba en condiciones de abonar el importe dictado desde la corte. Dicho de otro modo, cualquier situación de quiebra, malas cosechas, dudas administrativas, problemas con la Inquisición, etc. alimentaba el consabido argumento del "no cabimiento"16. Un ejemplo evidente de las muchas situaciones que podían dar lugar a no satisfacer el pago de libranzas lo encontramos en una orden dictada sobre el partido de Cáceres para que se pagase prorrateando una libranza de 320.000 a favor de la casa del infante don Fernando, debido a que la libranza original no se pudo satisfacer al encontrarse ausente el arrendador mayor y no tener nombrado hacedor ninguno ${ }^{17}$. La correspondiente provisión fue emitida el 20 de noviembre de

13 Sistema que, en esencia, continuó manteniéndose durante siglos.

14 Dedieu, J. P. y Ruiz Rodríguez, J. I.: "Tres momentos en la historia de la Real Hacienda", Cuadernos de Historia Moderna, $\mathrm{n}^{\circ} 15$ (1994), pp. 77-98.

15 Una descripción de la documentación hacendística generada por la administración en RoMERo MARTíNEZ, A.: Los papeles del fisco: estudio diplomático de la documentación fiscal castellana bajomedieval, Granada, Grupo Editorial Universitario, 1998.

16 Numerosos ejemplos en Suberbiola Martínez, J.: “Alcabalas de Málaga. Del arrendamiento al encabezamiento (1501-1518)”, Baetica. Estudios de Arte, Geografía e Historia, no 27 (2005), pp. 363-387 y GalÁn SÁnCHEZ, Á.: "Poder y fiscalidad en el reino de Granada tras la conquista: algunas reflexiones", Studia Historica. Historia Medieval, $\mathrm{n}^{\mathrm{o}} 30$ (2012), pp. 67-98.

17 Cédula para que las libranças questán echas en el partido de Cáçeres se paguen por rata. "Por parte de Juancho de Artiaga, pagador de la casa del ylustrysimo ynfante don Fernando, my muy caro e muy amado hijo, me fue fecha relaçión diciendo que le fueron librados en las rentas dese dicho partido este dicho año trezientas e veynte myll maravedís en qüenta de los año que ovo de aver para la paga de la cada del dcho ynfante. E como quier quel a ydo al dicho partydo a que le açebten la dicha librança e le paguen los dichos maravedís a los plasos ques obligado, e que no ha hallado en ese dicho partido al dicho Diego de Herrera [arrendador mayor] a cabsa que está absentado e no tiene fasedor que açebte ny pague en ese dicho partido [...] Vos mando a todos e cada vno de los que de los maravedís e otras cosas que las dichas rentas an montado e recudido e valido este dicho año, e de lo que montaren e recudieren e valieren las dichas rentas de lo que se pagan dellas el día de Sant Andrés al dicho Juancho de Artiaga [...] e a todas las otras libranças questán hechas en ese dicho partido acudan a cada una 
1509, es decir, al final del ejercicio. Dicho de otro modo, a partir de una cuestión particular se generaba un problema en el mecanismo de cobro cuya derivada evidente era la generación de obligaciones y débitos -tensiones en definitiva- sobre impuestos cuya recaudación era incierta a los ojos de los oficiales reales.

A esta realidad se le sumaba otro elemento de inestabilidad. Ya en aquellos momentos las cuentas de cargo y data se movían en un delicado equilibrio en tanto incluían las devoluciones de préstamos. Si acudimos, por ejemplo, a los datos de 1512 encontramos unos ingresos de 322.030 .000 maravedíes en concepto de rentas ordinarias, de los cuales se detraían los prometidos, las suspensiones y el situado -en este año alcanzaba los 127.384.000 maravedíes, es decir, un 39,43\% del total estimado para las rentas ordinarias de ese año. Descontadas para estas partidas, quedaban para librar algo menos de ciento ochenta millones de maravedíes ${ }^{18}$. Sabemos que las libranzas del reino alcanzaron ese año la suma de 90.000 .000 maravedíes $^{19}$, los cuales, junto a otros gastos en salarios, tenencias, acostamientos, ciertas mercedes, ejército en Nápoles, etc, sumaban 153.280.000 maravedíes. Obviamente, por tanto, la comparación entre ingresos y gastos deja en 1512 un "superávit" de algo menos de treinta millones de maravedíes para la expedición de libranzas.

Esta cantidad resultaba a todas luces insuficiente por el escaso margen de maniobra que existía ante cualquier imprevisto que pudiera acontecer. El cargo y data se elaboraba como una previsión teórica de ingresos y gastos en función de los precios de rentas por un lado y de los supuestos expendios a los que se tendría que hacer frente. Pero nada aseguraba que los tributos pudieran cobrarse en su totalidad, que se recaudasen en los plazos adecuados, que los grupos financieros estuviesen capacitados para hacer llegar el capital donde fuese oportuno, que los mismos financieros entregasen las partidas que les correspondían, que se imputasen gastos imprevistos, etc. Dicho de otro modo, el sistema se movía en un equilibrio muy precario pero, a la luz de las cifras, no se puede derivar que existiese un desequilibrio presupuestario grave, aunque sí riesgo de que cualquier incidencia alimentase los retrasos o los impagos. El licenciado Tello, en un importante memorial de estos años, hablaba ya de la necesidad de "saneamiento" de la hacienda, aserto que sin duda resultaría harto familiar con el paso de los decenios ${ }^{20}$.

Las causas que apuntaba el licenciado Tello, en esencia, estaban relacionadas con una organización de la administración hacendística que invitaba a manejos particulares en virtud de una Contaduría que obraba como una suma de grupos ${ }^{21}$. De hecho, como apunta el mismo memorial, cada oficial en cada grupo apuntaba por un lado presuponiendo que las libranzas siempre cabían pero, al no existir la coordinación

de las dichas por rata lo que les pertenesçiere e ovieren de aver conforme a las cartas de libramientos questán hechas en ese dicho partido [...]”. Archivo General de Simancas (AGS), Escribanía Mayor de Rentas (EMR), leg. 120.

18 Relación de lo que montan las rentas del reyno AGS, EMR, leg. 131-1.

19 Alonso García, op. cit. (nota 8), p. 92.

20 Memorial o estudio económico del licenciado Tello... "La mayor parte y avn el todo de la governaçión destos reynos y conseruaçión del estado dellos está en el saneamiento de la hazienda y conseruaçión de las rentas que tienen". Real Academia de la Historia (RAH), Salazar y Castro (SyC), A-8, f. 93r.

21 Ya Carande advirtió está realidad. CARAnde, R.: Carlos V y sus banqueros. 2. La hacienda real de Castilla, Barcelona, Crítica, 1990, pp. 47-66 (1 ${ }^{\mathrm{a}}$ ed., Madrid, 1949). Sobre el funcionamiento de la Contaduría en estos años remitimos a Alonso GARCíA, D.: "Organización de la hacienda real y poder financiero a principios del siglo XVI, en Bernal, A. M. (ed.): Modernidad de España, horizonte europeo y apertura americana, Madrid, Marcial Pons, 2017, pp. 687-700. 
debida con el otro agente en la contaduría, se tardaba meses y meses en expedir el documento, contribuyendo por tanto a generar un panorama de atrasos y deuda. Así lo expresaba el propio licenciado Tello haciendo referencia a un caso concreto que no tendría un buen final:

"Los ofiçiales de relaciones apuntan cada uno por sí unos a otros y otros a otros, de manera que quando un ofiçial viene a despachar una librança, como no tiene apuntado allí a el que el otro tiene, despáchala y diz que cabe el otro conforme a su libro y apuntamiento [...] y cada uno tiene por bueno su libro. Estase la librança por despachar así que en esto el daño de los librados y librantes es muy grande y tanto que no puede ser más. Ha venydo la diferençia a tanto que estando hechos libramientos para los acostamientos del año de siete más ha de un año y medio sobre quyen los ynbiara a Arévalo y a su partido"22.

Vemos por tanto que las cifras plasmadas en las cuentas generales que manejaba la Real Hacienda distaban de la realidad fiscal y financiera en la que se movía el reino. El modo de hacer frente a esta circunstancia no fue otro que el recurso constante al crédito, ordinario y extraordinario, aun a riesgo de entrar en situaciones de impago.

\section{El decreto de suspensión de libranzas de $\mathbf{1 5 0 9}$}

La suspensión de libranzas aquí analizada se firmó en Valladolid el 15 de febrero de 1509 con una instrucción muy clara: "no açebteys ny pagueys ninguna ny alguna de las libranças que [en] los dichos partidos están echas fasta oy día de la data desta mi carta a ninguna ny algunas personas syn que para ellos veades otra mi carta, no envargante cualesquier libramientos que vos sean mostrados e presentados" 23 . Formalmente se expidieron 12 cartas para los arrendadores, receptores, recaudadores mayores, tesoreros o escribanos de grupos de partidos organizados, aparentemente, por proximidad geográfica. Los partidos fueron los siguientes:

\begin{tabular}{|c|l|c|}
\hline $\begin{array}{c}\text { Número de } \\
\text { carta }\end{array}$ & \multicolumn{1}{|c|}{ Partidos } & $\begin{array}{c}\text { Precio de las rentas (1509) } \\
\text { (en maravedies) }\end{array}$ \\
\hline 1 & $\begin{array}{l}\text { Burgos, Candemuño, Cerrato, Castrojeriz, } \\
\text { Campoo, Cuatro Villas de Santander, } \\
\text { Laredo, Castrourdiales, San Vicente de la } \\
\text { Barquera, merindad de Rioja, merindad } \\
\text { de Allendebro, Vitoria, villa de Miranda y } \\
\text { salinas de Burandón. }\end{array}$ \\
\hline 2 & $\begin{array}{l}\text { Campos con Palencia, Barcial de la } \\
\text { Loma, Carrión, Saldaña, Osma, Segovia, } \\
\text { Sepúlveda, Ávila y su obispalía. }\end{array}$ & 16.826 .886 \\
\hline
\end{tabular}

\footnotetext{
22 Alonso García, op. cit. (nota 8), p. 147. RAH, SyC, A-8, f. 93v. Memorial o estudio económico del licenciado Tello...

23 Vid apéndice I, donde transcribimos íntegramente el documento.
} 


\begin{tabular}{|c|c|c|}
\hline 3 & $\begin{array}{l}\text { Medina del Campo, Salamanca, Toro, } \\
\text { Zamora, Astorga, Ponferrada. }\end{array}$ & 21.719 .355 \\
\hline 4 & Santiago, Orense, Lugo, Mondoñedo. & 15.270 .730 \\
\hline 5 & $\begin{array}{l}\text { Madrid, Ocaña y los otros lugares de la } \\
\text { Provincia de Castilla, Bailía del Alcázar, } \\
\text { Salinas de Espartinas, Alcalá de Henares, } \\
\text { Uceda, Yepes, Lillo, La Guardia, El } \\
\text { Romeral, Talavera, Campo de Calatrava, } \\
\text { Zorita, Calatrava del Andalucía. }\end{array}$ & 24.736 .073 \\
\hline 6 & $\begin{array}{l}\text { Guadalajara, Servicio y Montazgo, Salinas } \\
\text { de Atienza, Molina, Cuenca, Marquesado } \\
\text { de Villena, Grana del Marquesado, Alcaraz. }\end{array}$ & 20.335 .074 \\
\hline 7 & $\begin{array}{l}\text { Murcia, Segura de la Sierra, Almedina y } \\
\text { Torrenueva. }\end{array}$ & 4.418 .080 \\
\hline 8 & $\begin{array}{l}\text { Trujillo, tercias de Plasencia, Badajoz, } \\
\text { Hierbas de Calatrava. }\end{array}$ & 3.916 .075 \\
\hline 9 & $\begin{array}{l}\text { Rentas mayores de Córdoba, rentas } \\
\text { menores, alhóndiga de Córdoba, } \\
\text { almojarifazgo castellano, La Rambla y } \\
\text { Santaella, almojarifazgo mayor de Castilla, } \\
\text { alhóndiga de Sevilla, madera, tres rentas, } \\
\text { diezmo del aceite, tercias del pan, tercias de } \\
\text { maravedíes, Sierras de Aroche [sic], tercias } \\
\text { de Carmona, Écija, Teba y Ardales, Jerez } \\
\text { de la Frontera, Cádiz, Canarias y Gibraltar. }\end{array}$ & 52.543 .763 \\
\hline 10 & $\begin{array}{l}\text { Llerena, Jerez de Badajoz, Fuente el } \\
\text { Maestre. }\end{array}$ & 4.542 .909 \\
\hline 11 & $\begin{array}{l}\text { Baeza, Úbeda, adelantamiento de Cazorla, } \\
\text { Andújar, Quesada, Jaén. }\end{array}$ & 10.696 .248 \\
\hline 12 & $\begin{array}{l}\text { Alcaicería de Granada, rentas mayores, } \\
\text { rentas menores, hagüela, habices, diezmos } \\
\text { de Granada, diezmos de las Alquerías, } \\
\text { salinas de Granada, seda [de Granada] y } \\
\text { Alpujaras, alcabalas y diezmos. }\end{array}$ & 18.527 .433 \\
\hline \multirow[t]{2}{*}{13} & $\begin{array}{l}\text { Málaga (alcabalas y diezmos), Baza } \\
\text { (alcabalas y diezmos), Guadix, Almería y } \\
\text { Purchena. }\end{array}$ & 8.148 .436 \\
\hline & TOTAL & 199.780 .599 \\
\hline
\end{tabular}

Fuente: Apéndice I y AGS, EMR, legs. 118-120. 


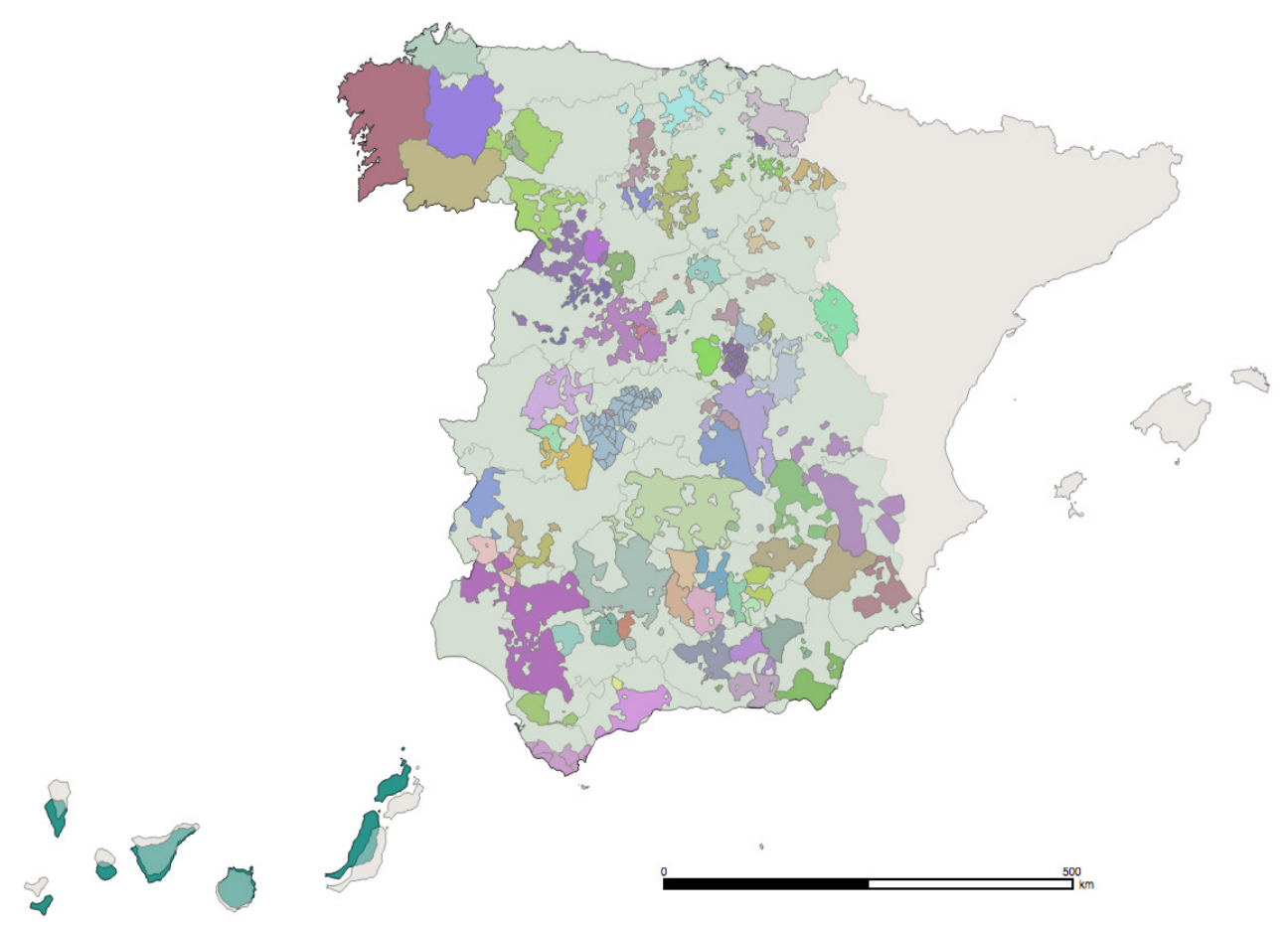

Mapa 1: Partidos afectados por la suspensión de libranzas ${ }^{24}$

Esta suspensión de libranzas afectó a partidos diseminados por todo el reino, desde Galicia al archipiélago canario. La medida se extendió a un total de 88 partidos de los aproximadamente 169 que componían el mapa fiscal de la corona de Castilla ${ }^{25}$. Vemos en la siguiente tabla los partidos que en principio no sufrieron el decreto, si bien hay que advertir que es posible que la suspensión también pudiera haberse extendido a estas circunscripciones y simplemente no ha sido posible localizar hasta el momento la documentación que así lo acredite. De hecho, hemos accedido a una carta de desembargo expedida sobre el partido de Montes de Oca, el cual, en principio, no estaba incluido entre las zonas afectadas ${ }^{26}$. Incluimos en cualquier caso los partidos sobre los que se han localizado cartas de suspensión:

\footnotetext{
24 Fuente: Tabla 1. La configuración de partidos ha seguido el esquema propuesto por AlOnso GARcíA, D.: "Crear espacios, cobrar impuestos. Los partidos fiscales de Castilla a comienzos de la Edad Moderna", en SALAS Almela, L. (ed.): Los ámbitos de la fiscalidad: fronteras, territorios y percepción de tributos en los imperios ibéricos (siglos XV-XVIII), Madrid, Instituto de Estudios Fiscales, 2012, pp. 41-56.

25 Alonso García, op. cit. (nota 8), pp 29-30.

26 Vid apéndice II, Francisco de Costaña.
} 


\begin{tabular}{|c|c|c|}
\hline PARTIDO & PARTIDO & PARTIDO \\
\hline Bureba & Lugares de Laonor de Sedano & Montes de Oca \\
\hline Monzón & Pernia & Sahagún \\
\hline Villadiego & Villaumbrales & Ágreda \\
\hline Castillejo & Berlanga & Caracena \\
\hline Guipúzcoa & Rojas/Tormantos & Santo Domingo de Silos \\
\hline Valdearana & Vizcaya & Arévalo \\
\hline Condado de Urueña & Lugares de Antonio Franco & $\begin{array}{c}\text { Lugares de Gutierre de } \\
\text { Robles }\end{array}$ \\
\hline Madrigal & Olmedo & Peñaranda/Fuentelsol \\
\hline Tordesillas & Valladolid & Villanueva/San Román \\
\hline Abadías de San Isidro & Ciudad Rodrigo & León \\
\hline Lugares de Juan de Vega & Valdeguareña & Asturias \\
\hline Avilés & Cangas/Tineo & Castropol \\
\hline Llanes & Lugares Confiscados & Vivero \\
\hline Brihuega & Ciudad Real & Cubas \\
\hline Fuensalida & Illescas & Toledo \\
\hline Utrilla/Almauez & Villarejo de Fuentes & Alcudia/La Serena \\
\hline Cáceres & Iglejuela & Salvatierra \\
\hline Villanueva de Barcarrota & Alcántara & Bédmar \\
\hline Estepa & La Higuera & Provincia de León \\
\hline Alanís & Condado de Niebla & Lora \\
\hline Purchena & Utrera & Condado de Santiesteban \\
\hline Fuenteovejuna & Luque & Término Realengo \\
\hline Cartagena & Almuñécar & Huéjar/Pinillos \\
\hline Valle de Lecrín & & \\
\hline
\end{tabular}

Podemos imaginar la importancia de esta suspensión tanto a nivel estrictamente fiscal como desde la perspectiva de los damnificados, que de este modo se verían acuciados por la imposibilidad de recoger su correspondiente salario, quitación o atraso, como muestra una petición de Álvaro de Mercado a la mismísima reina ${ }^{27}$. De hecho, la documentación habla sistemáticamente de "embargo general de rentas", por lo que cabe no descartar que lo mismo otras cartas no localizadas extendiesen la medida a otras demarcaciones tributarias.

Cierto es que se venían dando suspensiones de situado desde hacía tiempo ${ }^{28}$. Ahora, en cambio, se trataba de una suspensión de libranzas. Las cuantías del decreto de

27 Petición de Álvaro de Mercado. "Muy poderosa señora. Dize Áluaro de Mercado, corregidor de la villa de Carmona, por vuestra altesa que a él le fueron librados 93.333 por dos cartas de libramiento que Gómes de Córdoua, recaudador de una dozaua parte del almoxarifazgo mayor de Seuylla, el qual açebtó las dichas libranças. E agora el dicho Gómez de Córdoua dize que no las puede pagar por virtud de vna reuocatoria general que de las libranças del año de 509 se fizo. Suplica a vuestra alteza mande pues a él le son deuydos del año de 506, 507 y syempre ha estado en el seruicio de vuestra alteza y está. Mande declarar el dicho embargo no se entienda a sus libranças [...]”. AGS, EMR, leg. 119.

28 Solo a modo de ejemplo, AGS, Registro General del Sello (RGS), febrero-1508, fols. 49 y ss., si bien cualquiera de los meses conservan documentación similar. Cfr. Solinís Estallo, M. Á.: "Los libramientos reales durante la segunda mitad del siglo XV a través de los Cuadernos de Alcabalas y las Cortes", en Fortea PÉrez, J. I. y Cremades Griñán, C. M. (eds.): Política y hacienda en el Antiguo Régimen. II Reunión Cientifica de la Asociación Española de Historia Moderna, vol. I, Murcia, Universidad de Murcia, 1993, pp. 581-591. 
febrero de 1509 hablan por sí mismas. La medida afectó a partidos que aportaban al tesoro unos doscientos veinte millones de maravedíes -un $68,75 \%$ respecto al importe total de las rentas ordinarias ${ }^{29}-$, los cuales, insistimos, se hallaban diseminados por todo el reino. Por cuantías afectó especialmente a la zona de Sevilla, lo que no es extraño ya que el espacio hispalense era el que más aportaba a la real hacienda. También destaca en este punto Granada, la zona centro de Castilla y los territorios de órdenes militares. Estas cuantías, en cualquier caso, no se corresponden con el total afectado por la suspensión ya que estos se aplicaban únicamente a libranzas -con la excepción de las Guardas- y no a los situados.

La mayor parte de los partidos que (en principio) no sufrieron el embargo de sus libranzas fueron pequeños núcleos de población, en no pocas ocasiones de vinculación nobiliaria. En cualquier caso también encontramos ausencias muy significativas tanto por volumen de rentas como la relevancia del propio enclave. Nos referimos principalmente a ciudades como Toledo, Valladolid, León y su entorno, Cáceres o Tordesillas, las cuales, como decimos, no se incluyeron en la suspensión de las libranzas. Tampoco lo hizo alguna región entera como fue el caso de Asturias.

¿Cómo cabe interpretar la suspensión de libranzas? A nuestro entender fue un intento de Fernando el Católico por poner orden en el sistema de pagos y asentar su capacidad de influencia sobre el sistema fiscal en su conjunto. La orden se dictó coincidiendo con la estancia del rey aragonés en Valladolid, donde se organizaron diferentes actos ceremoniales que venían a reivindicar su figura ${ }^{30}$. Recordemos aquí que 1509-1510 fueron años importantes en la gobernabilidad del reino con varios acontecimientos que refrendaron la posición política de Fernando el Católico. Nos referimos en este punto a III Tratado de Blois y las Cortes de Madrid, momento en el que la parte austriaca reconoció el derecho del monarca aragonés a ser rector principal de los destinos de Castilla, reafirmándose con ello su figura como principal referente político en Castilla ${ }^{31}$.

El estado de la hacienda en 1509 parecía sumirse en una situación anómala -vista desde una perspectiva estatal-, siempre atemperada por la capacidad del mundo financiero de seguir allegando crédito en concomitancia con los grupos de las contadurías. El imponente papel del mundo financiero en la recaudación y gestión de impuestos no aseguraba la correcta circulación entre adelantos, recuperación monetaria y nuevos adelantos a la corona por parte de las compañías de arrendadores o los tesoreros de encabezado. Las quiebras de compañías no eran inhabituales, en ocasiones con episodios tan notables como la caída del grupo de Gonzalo del Puerto. Veamos la siguiente cédula de noviembre de 1508, donde constan impagos desde hacía varios años y, quizás lo que fuera más grave, el reconocimiento implícito por parte de la corona de las enormes dificultades que encontraba para controlar su propia hacienda:

"El rey. Contadores mayores. Bien sabeys como por una mi çédula os e mandado que suspendieses a Juan de la Fuente, recaudador de la seda de Granda, 1.000.000 de maravedíes señaladamente de las libranças que tenya por pagar del dicho su cargo de los años de 507, 508 cada año 500.000 açebtando [sic] las libranças de

Alonso García, op. cit. (nota 8), p. 25.

30 Ladero Quesada, M. Á.: Los últimos años de Fernando el Católico, Madrid, Dykinson, 2016, pp. 150-152.

31 Carretero Zamora, J. M.: "La Concordia de Blois de 1509 y los acuerdos para la gobernación de Castilla", en Hernán Cortés y su tiempo: actas del Congreso "Hernán Cortés y su tiempo", V Centenario (1485-1985), Mérida, Editora Regional de Extremadura, 1987, pp. 528-537. 
las guardas para que se pagase el dicho 1.000 .000 a çiertos plazos segund en la dicha çédula se contiene. E agora el dicho Juan de la Fuente me fizo relaçión que no le suspendeys el dicho 1.000 .000 de maravedíes a cabsa que yo mandé que no se supendiesen las dichas libranças que están fechas al Duque e Duquesa de Villaermosa, e que las otras libranças el dicho recaudador dezía que las tenya pagadas por manera que no avía de donde suspender el dicho 1.000.000. Por ende yo vos mando que suspendáis el dicho 1.000 de las libranças del año de 509 años con tanto que no sean de las que están fechas a las guardas $[\ldots]^{\prime 32}$

Vemos a partir de este ejemplo puntual el "desorden en el régimen de Contadurías" (parafraseando a Carande) que imperaba en aquellos momentos. Por una parte quedaban por pagarse libranzas de 1507 y 1508, trasladadas a las guardas como objetivo prioritario de gasto (por el ejército y también para sostener el ecosistema financiero que permitía volver a poner en marcha los mecanismos de arrendamientos/ obligaciones al año siguiente). Lo curioso de este caso es que los contadores no quieren suspender la libranza a los Duques de Villahermosa pero, al ser transferido esta partida a las guardas y haberse satisfecho el abono de los otros títulos, el arrendador se queja que ya no tiene donde pagar, entrando por tanto en el argumento del no cabimiento. La suspensión de libranzas implicó en este caso -y otros muchos- que se atrasase el pago hasta finales de 1510 o en 1511, según consta en una orden de 4 de agosto de 1509. Curiosamente, sólo dos días después el propio Fernando el Católico se desdecía y ordenaba que se desembargasen estas mismas libranzas ${ }^{33}$.

La gestión de esta suspensión de libranzas no fue fácil ya que se entremezclaban situaciones muy diversas junto a un elemento que nunca debe olvidarse: el decreto incluía notables excepciones, comenzando por los propios pagos a las guardas, que en principio por tanto continuaban funcionando al margen de la medida. Esto mismo sirvió para que Juan de Torres, alcaide de la fortaleza de Ponferrada, elevase una petición de desembargo -concedida- por valor de 310.000 maravedíes, argumentando que su libranza acostumbraba a expedirse junto a las de Francisco de Vargas -es decir, guardas-, que en este caso se hallaba exentas de la medida ${ }^{34}$. Al menos en este caso valió tanto el concepto como el modo por el que se expedía la documentación, lo que incluía otro factor que en ningún caso aparecía en las cartas de suspensión. Diego de Vera, por poner otro ejemplo, consiguió que una libranza de 386.250 maravedíes finalmente pudiera ser cobrada en su nombre por el tesorero general -ahora convertido en agente de negocios- en satisfacción de un abono previo que le había realizado el susodicho Diego de Vera ${ }^{35}$.

Asimismo cabe resaltar que la orden de suspensión sirvió de argumento a los arrendadores para evitar el pago de libranzas aunque apareciesen expresamente excluidas de embargo en las cartas enviadas a arrendadores y tesoreros. Así al menos sucedió en el caso de la Capilla Real de Granada, en principio libre de la suspensión. En cambio, los propios financieros no quisieron pagar estas cuantías "diziendo que todas las libranças fechas en las rentas destos reynos deste presente año están envargadas" ${ }^{36}$. Este caso demuestra por sí mismo que la gestión del embargo se

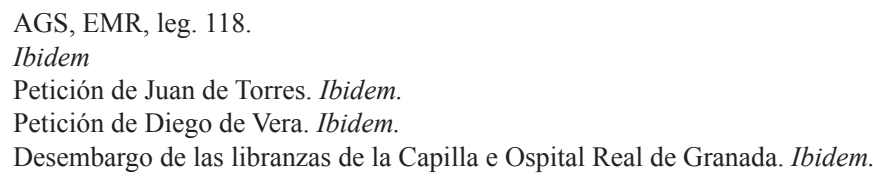


nutrió de interpretaciones generosas, por decirlo de algún modo, por parte de los financieros, lo que de algún modo les podría favorecer en los mecanismos de recuperación de crédito.

\section{Las cartas particulares de desembargo.}

Uno de los elementos más curiosos de esta suspensión de pago de libranzas se relaciona con la provisión de cartas de desembargo que se empezaron a emitir apenas unas semanas después de dictarse la orden de retención. No nos referimos en este apartado a las excepciones incluidas en el decreto original sino a un buen número de órdenes particulares que otorgaban el privilegio de seguir cobrando a pesar de estar inmersos en una situación de embargo obligatorio de libranzas. Una de las órdenes más importantes fue la expedida el 14 de abril de 1509, por la cual se mandaba desembargar cualquier libranza a gente que hubiera luchado en Nápoles y que sus libranzas se abonasen en 1510 sobre partidos donde tuvieran cabimiento ${ }^{37}$. Observamos aquí dos de las características más importantes de este tipo de peticiones y, por extensión, de la propia suspensión: atraso del pago hasta 1510 y revisión de las consignaciones sobre rentas determinadas, donde nuevamente cabe apreciar el intento de Fernando el Católico por ordenar el estado de la hacienda y reivindicar su papel en torno a la misma.

En general, estas cartas de desembargo se otorgaban ante una petición de parte. Por ellas el propio rey aragonés se desdecía de la suspensión de libranzas para ordenar que el particular en cuestión pudiese cobrar el correspondiente abono sobre un determinado partido. Se registraron numerosísimas "cartas" de desembargo donde el rey, en suma, intentaba ejercer su patronazgo favoreciendo a quien estimase oportuno $^{38}$. La consecuencia es obvia: no pasó demasiado tiempo hasta que Fernando el Católico comenzase a dictar un buen número de cédulas donde, básicamente, se reservaba al beneficiario de turno la posibilidad de seguir cobrando las libranzas "no embargante el embargo que está fecho en las libranças fechas en las rentas destos reynos". Este aserto se repite sistemáticamente en las órdenes de desembargo.

El importe de estas excepciones no parece excesivo (en torno a unos 6-7 millones de maravedíes sin contar las partidas de Nápoles). Los partidos concernidos se repartían por toda la geografía peninsular, si bien con tendencia a concentrar estos desembargos sobre Granada o el entorno de Ávila. Una parte de estas cédulas tuvieron como objeto el pago a los alcaides de las fortalezas de Simancas, Huete, Ávila, Burgos, Baza, Écija, Benzalema, Benamaruel, Ponferrada, Rabe ${ }^{39}$, en ocasiones a gente tan importante como Diego Pérez de Santisteban, criado de don Enrique Enríquez y comendador de las fortalezas de Baza, Écija, Benzalema, Banamaruel y Zújar, don Juan de Torres como tenente del enclave de Ponferrada o el mismísimo

"El rey. Contadores mayores. Yo vos mando que todos los mrs. que están librados en las rentas dese presente año de la fecha de esta mi çédula a qualesquier personas asy de los que syrvieron en el reygno de Nápoles como en otra manera e por vosotros está enbargado se lo mudades a qualesquier rentas destos reygnos del año venidero de quinientos e diez años, e para la cobrança dellos dad las cartas de libramientos e otras prouisyiones que menester ouyere". AGS, EMR, Cámara de Castilla (CC), Libros de Cédulas (LC), 1. 17, f. 316.

38 Vid apéndice II.

39 Sobre las tenencias en Castilla en esta época, Quintanilla Raso, M. I.: "La tenencia de fortalezas en Castilla durante la Baja Edad Media”, En la España Medieval, T. V (1986), pp. 861-896. 
Gonzalo Chacón por sus desempeños al frente de la fortaleza de Ávila. El importe de estos pagos destinados a los alcaides de castillos rondaría el millón de maravedíes, lo que no era poca cosa si pensamos que el coste anual por este concepto se estimaba en unos diez millones ${ }^{40}$.

Los otros capítulos de desembargos hacen referencia a salarios destinados a personal de la corte, cargos en el territorio y otros por servicios de guerra en Italia o África. En no pocos casos las cédulas favorecieron a determinados continos, como fue el caso de Pedro Gaitán, Pedro Berrio, Pedro Ludeña, Rui Díaz de Porras o don Diego de Toledo, hijo del duque de Alba, a quien se le expidió el desembargo por su asignación de contino "no enbargante que no aya residido [en la corte]". El cronista Gonzalo de Ayora también fue beneficiario de una cédula expedida en noviembre de 1509.

Si bien estas cédulas de desembargo no acostumbran a incluir excesivos detalles sobre las operaciones en curso, en algún caso es posible detectar condiciones que demuestran que aquella operación se realizó no sin enormes contradicciones entre los diferentes textos. Así, a Gutiérre Gómez de Fuensalida se le expidió cédula de desembargo en calidad de corregidor de Granada con la condición de que se le abonase esta partida "no embargante qualesquier libranzas que en los dichos partidos [Granada] estén fechas". Obsérvese en este punto que el propio monarca no sólo rectificaba la suspensión de libranzas sino también las propias excepciones incluidas en el decreto de suspensión -reserva al pago de Guardas, principalmente-, hecho que no podría sino generar más confusión. En otros casos, como ocurrió con el desembargo realizado al conde de Tendilla, se dictó con condición que, en caso de haber sido previamente librado para guardas, ahora se debería extraer de este capítulo para asignárselo directamente a Tendilla. El arrendador o tesorero que recibiese este tipo de documentos no estaría en una posición fácil a la hora de elegir a quién o cómo pagar habida cuenta la proliferación de órdenes y contraórdenes que, como decimos, parece caracterizar a esta suspensión de libranzas. La cédula de desembargo a don Juan de Mendoza también se realizó sobre un dinero previamente librado a las guardas, con el matiz que a los propios contadores se les hubo de insistir para que buscaran la consignación en rentas diferentes a las que constaban en el libramiento original.

Naturalmente, la lógica de estas cédulas de desembargo no hay que buscarla en ningún tipo de "racionalidad" administrativa sino en el ejercicio de la potestad regia en un momento de afirmación de autoridad por parte de Fernando el Católico. La mayor parte de los beneficiarios fueron gente cercana a sus círculos de poder. En otros casos, en cambio, las cartas de desembargo se expidieron a gente del entorno de Felipe I. Así sucedió con Andrés de Ribera, alcaide de la fortaleza de Burgos, vinculado incluso familiarmente a don Juan Manuel ${ }^{41}$. Las cédulas se conseguían o podían conseguir a partir de diferentes polos de influencia en la corte, que por definición eran muy diversos. Hubo, por ejemplo, una cédula de desembargo dictada a favor del prior de San Juan para cuya expedición fue clave la mano del Cardenal Cisneros ${ }^{42}$. Dado que la organización de la Contaduría de Hacienda se articulaba en función de los grupos urdidos en torno a cada uno de los contadores mayores, a cuyos oficiales

40 LAdero Quesada op. cit. (nota 3), p.57.

${ }^{41}$ Cooper, E.: "La Iglesia y los comuneros: una interpretación anti-señorial”, en Martínez GiL, F (coord.): En Torno a las Comunidades de Castilla: acta del Congreso Internacional "Poder, Conflicto y Revuelta en la España de Carlos I”, Toledo, Universidad de Castilla la Mancha, 2002, p. 302.

42 Alonso García, op. cit. (nota 8), p. 256. 
en concreto se elevaban las peticiones individuales para su posible tramitación, no resulta baladí acercarse al nombre de los oficiales de relaciones que aparece en la documentación:

\begin{tabular}{|c|c|c|c|}
\hline OFICIAL & BENEFICIARIOS & CONTADURÍA & SECRETARIO \\
\hline Somonte, Suero & $\begin{array}{l}\text { Pérez de Santisteban, } \\
\text { Diego } \\
\text { Olano, Sebastián de } \\
\text { Torres, Juan de (don) } \\
\text { Sánchez, Luis } \\
\text { Berrio, Pedro de } \\
\text { Gaitán, Pedro } \\
\text { Santos, Pedro de los } \\
\text { Cárdenas, Diego de } \\
\text { López de Lemos, } \\
\text { Alonso } \\
\text { Boticario, Jaime }\end{array}$ & $\begin{array}{l}\text { Juan Velázquez de } \\
\text { Cuéllar }\end{array}$ & $\begin{array}{l}\text { Miguel Pérez de } \\
\text { Almazán } \\
\text { Juan López } \\
\text { Miguel Pérez de } \\
\text { Almazán } \\
\text { Miguel Pérez de } \\
\text { Almazán } \\
\text { Hugo de Urriés } \\
\text { Lope Conchillos } \\
\text { Miguel Pérez de } \\
\text { Almazán } \\
\text { Conchillos, Lope }\end{array}$ \\
\hline Suárez, Cristóbal & $\begin{array}{l}\text { Arceo, Fernando de } \\
\text { Marqueses de Moya } \\
\text { Ludeña, Pedro } \\
\text { Mendoza, Juan de } \\
\text { (don) } \\
\text { Jerez, Francisco de }\end{array}$ & Antonio de Fonseca & $\begin{array}{l}\text { Hugo de Urriés } \\
\text { Miguel Pérez de } \\
\text { Almazán } \\
\text { Miguel Pérez de } \\
\text { Almazán } \\
\text { Miguel Pérez de } \\
\text { Almazán }\end{array}$ \\
\hline $\begin{array}{l}\text { Velázquez de Cuéllar, } \\
\text { Juan }\end{array}$ & $\begin{array}{l}\text { Gómez de Fuensalida, } \\
\text { Gutierre } \\
\text { Díaz de Porras, Rui }\end{array}$ & $\begin{array}{l}\text { Juan Velázquez de } \\
\text { Cuéllar }\end{array}$ & Lope Conchillos \\
\hline
\end{tabular}

Suero de Somonte era oficial en la contaduría de Juan Velázquez de Cuéllar, quien también aparece presente en algunas cédulas. Al menos doce cédulas pasaron por este grupo mientras que únicamente cinco se tramitaron con el concurso de Cristóbal Suárez, esto es, la contaduría de Antonio de Fonseca, de lo que cabe inferir que su grupo tuvo una participación inferior en este asunto. 


\section{Las consecuencias del embargo. Estado de las rentas en 1511.}

La suspensión de libranzas de 1509 no tuvo el efecto esperado de reducir la incertidumbre o problemas de cobro que se venían arrastrando desde hacía bastante tiempo. La realidad hacendística distaba de los números que manejaba la administración, tanto antes como después de la suspensión. De hecho encontramos en estos años otros intentos que despejar el camino de las deudas o los impagos, como fueron la renegociación de las albaquías con diferentes agentes o nuevos acuerdos financieros para inyectar liquidez a la hacienda pública ${ }^{43}$. No parece que los problemas de atrasos o impagos fuesen resueltos; en la "nómina general" de 1511 parte con un expresivo "no ay para poder cumplir con todos enteramente" ${ }^{4}$. El finca para librar alcanzó en ese año los 175 millones de maravedíes, a los que se sumaron otros cincuenta procedente del servicio de Cortes. Su destino fue el siguiente:

\begin{tabular}{|c|c|c|c|}
\hline CONCEPTO & CUANTÍA & CONCEPTO & CUANTÍA \\
\hline $\begin{array}{l}\text { Acostamientos hasta finales } \\
\text { de } 1510\end{array}$ & 15.800 .000 & Acostamientos de caballeros & 4.170 .000 \\
\hline Tenencias de años pasados & 16.960 .000 & Acostamientos de regidores & 635.000 \\
\hline $\begin{array}{l}\text { Deudas de Mazalquivir y otras } \\
\text { deudas de gente del sueldo }\end{array}$ & 1.750 .000 & Ochoa de Landa, descargos & 5.450 .000 \\
\hline $\begin{array}{l}\text { Pedro García de Atienza para } \\
\text { obras en la capilla de Atienza }\end{array}$ & 3.050 .000 & $\begin{array}{l}\text { San Juan de los Reyes, } \\
\text { Fernando de Vega y otras } \\
\text { personas de libranzas para } \\
\text { obras }\end{array}$ & 1.040 .000 \\
\hline $\begin{array}{l}\text { A ciertas personas que le } \\
\text { están librados por otros tantos } \\
\text { prestaron al rey don Felipe }\end{array}$ & 1.410 .000 & $\begin{array}{l}\text { Corregidores y alcaldes y otros } \\
\text { oficiales por quitaciones }\end{array}$ & 1.070 .000 \\
\hline $\begin{array}{l}\text { Otras libranzas ordinarias de } \\
\text { merced de tres en tres años }\end{array}$ & 3.150 .000 & $\begin{array}{l}\text { Libranzas de situados que no } \\
\text { cupieron y situados que se } \\
\text { compraron del rey don Felipe }\end{array}$ & 600.000 \\
\hline Gastos extraordinarios & 1.700 .000 & Deudas de Nápoles & 6.120 .000 \\
\hline $\begin{array}{l}\text { Libranzas de continos de } \\
\text { deudas que se les debe hasta } \\
1506(*)\end{array}$ & 6.120 .000 & Guardas $(*)$ & 75.000 .000 \\
\hline $\begin{array}{l}\text { Gastos extraordinarios del } \\
\text { estado del reino }(*)\end{array}$ & 15.000 .000 & $\begin{array}{l}\text { Sueldo de Orán, Bujía y otros } \\
\text { gastos de guerra }(*)\end{array}$ & 20.000 .000 \\
\hline $\begin{array}{l}\text { Casa del infante don Fernando } \\
(*)\end{array}$ & 3.700 .000 & $\begin{array}{l}\text { Cristóbal Suárez para la paga } \\
\text { de los del Consejo, alcaldes, } \\
\text { secretarios, físicos, alguaciles y } \\
\text { personal de la Contaduría }(*)\end{array}$ & 7.500 .000 \\
\hline
\end{tabular}

43 Ibidem, pp. 257-270; ORTEGA CERA, Á.: "La recaudación de las albaquías: un entramado financiero en el reinado de Juana I de Castilla", en Collantes de TERÁn, A. (ed.): Fuentes para el estudio del negocio fiscal y financiero de los reinos hispánicos (siglos XIV-XVI), Madrid, Ministerio de Hacienda-Instituto de Estudios Fiscales, 2010 , pp. 205-227.

44 AGS, EMR, Nóminas de Corte (NC), leg. 1-2, f. 395. 


\begin{tabular}{|c|c|c|c|}
\hline Infante don Enrique $(*)$ & 1.000 .000 & $\begin{array}{l}\text { Escuderos que viven de } \\
\text { acostamiento }(*)\end{array}$ & 6.000 .000 \\
\hline Tenencias del reino $(*)$ & 5.500 .000 & Acostamiento de caballeros $(*)$ & 2.000 .000 \\
\hline $\begin{array}{l}\text { Gobernador y alcaldes de } \\
\text { Galicia, corregidores de } \\
\text { Granada, Toledo, Cádiz, } \\
\text { Gibraltar, Ponferrada, Santo } \\
\text { Domingo de la Calzada } \\
\text { y Tordesillas, junto a los } \\
\text { alcaldes mayores de los } \\
\text { adelantamientos de Castilla, de } \\
\text { León y los otros que se suelen } \\
\text { librar }(*)\end{array}$ & 1.920 .000 & $\begin{array}{l}\text { Dotaciones de las iglesias de } \\
\text { Granada, Málaga, Guadix y } \\
\text { Almería }(*)\end{array}$ & 3.500 .000 \\
\hline Deudas de continos $(*)$ & 2.500 .000 & $\begin{array}{l}\text { Duque de Villahermosa, } \\
\text { marqueses de Moya y a don } \\
\text { Juan de Ribera y otros, por } \\
\text { nómina }(*)\end{array}$ & 2.600 .000 \\
\hline $\begin{array}{l}\text { Escribanías de encabezado que } \\
\text { se han de recibir en cuenta }(*)\end{array}$ & 600.000 & $\begin{array}{l}\text { Lo que se debe a los criados y } \\
\text { monteros de la reina }\end{array}$ & 1.000 .000 \\
\hline $\begin{array}{l}\text { Libranzas inciertas para las } \\
\text { obras de Capilla Real de } \\
\text { Granada }\end{array}$ & 1.350 .000 & $\begin{array}{l}\text { Iglesias de Granada y Almería } \\
\text { que se les debe de sus } \\
\text { dotaciones }\end{array}$ & 1.100 .000 \\
\hline $\begin{array}{l}\text { Libranzas a los marqueses de } \\
\text { Moya que se les debe de } 1509\end{array}$ & 600.000 & $\begin{array}{l}\text { Doña María de Tovar por cierto } \\
\text { situado comprado al rey don } \\
\text { Felipe }\end{array}$ & 700.000 \\
\hline $\begin{array}{l}\text { Luis Sánchez, en cuenta de } \\
\text { lo que se debía al tesorero, } \\
\text { su padre, Gabriel Sánchez } \\
\text { del sueldo de una Carraca en } \\
\text { Nápoles }\end{array}$ & 800.000 & $\begin{array}{l}\text { Guillén Márquez en cuenta } \\
\text { de } 400.000 \text { de dos cargos del } \\
\text { almojarifazgo de Sevilla de } \\
1509 \text { que se le suspendieron }\end{array}$ & 200.000 \\
\hline $\begin{array}{l}\text { Comendador Gutiérrez Gómez } \\
\text { de Fuensalida, corregidor de } \\
\text { Granada }\end{array}$ & 300.000 & $\begin{array}{l}\text { Libranzas inciertas de } \\
\text { escuderos de acostamientos }\end{array}$ & 200.000 \\
\hline $\begin{array}{l}\text { Duque de Villahermosa de } \\
\text { lo que saliere incierto de las } \\
\text { libranzas de } 1510 \text { hechas } \\
\text { sobre el diezmo del aceite y } \\
\text { almojarifazgo de Sevilla }\end{array}$ & 600.000 & $\begin{array}{l}\text { Herederos de Sancho de } \\
\text { Córdoba que se le deben del } \\
\text { salario de capitán. }\end{array}$ & 182.000 \\
\hline Infantes de Granada & 300.000 & & \\
\hline $\begin{array}{l}\text { TOTAL GASTOS } \\
\text { EXTRAODINARIOS: }\end{array}$ & 70.025 .000 & $\begin{array}{l}\text { TOTAL GASTOS } \\
\text { ORDINARIOS }(*)\end{array}$ & 155.502 .000 \\
\hline
\end{tabular}

(*) gastos ordinarios

Como se puede observar, los más de 220 millones de maravedíes resultantes de la suma de gastos ordinarios y cuantías extraordinarias, en muchos casos atrasos sobre pagos que no se pudieron realizar anteriormente, superaba en más de un $20 \%$ al capital dinero disponible para realizar los pagos procedente de la hacienda ordinaria. El importe de los gastos extraordinarios ascendía a cerca del $46 \%$ respecto al dispendio presupuestado, incluyéndose, como hemos apuntado, numerosas partidas de 
atrasos. A nuestro entender la situación era más grave de lo que se puede desprender de estos datos: en el total de gastos ordinarios entró la libranza de guardas. Dicho de otro modo, se reconocía un importante monto de gastos debidos -extraordinarios- sin que a priori cupiera sacarse de la principal partida de la hacienda, que en aquellos momentos no era otra que las rentas ordinarias. El propio documento reconocía que se intentaba evitar el pago de deudas sobre ingresos de años venideros:

"Porque fasta aquy se acostunbra librar las debdas que se deven en las rentas de los años venideros, e después, para conplir las cosas del estado real destos reynos de neçesidad se an de revocar las dichas libranças e tornarla a mudar e librar [a] otros años, de que los librados resçiben daño e se les syguen muchas costas e gastos e avn a cabsa desto ha avido algunos pleitos e debates entre los librados e otras personas con quien baratan sus libranças como se ha visto por yspirençia. E por evitar esto mando a vos los dichos nuestros contadores mayores que ninguna ny algunas debdas que se devan e libranças que se hayan de hazer demás de lo suso contenidas no las libreys en ninguno de los años venideros"

Para evitar la pignoración de débitos sobre rentas futuras se proponía como solución acudir al servicio y buscar una cierta centralización en el pago de estas libranzas, lo que a su vez se relaciona con el crecimiento político de Francisco de Vargas ${ }^{46}$. La propia historia de la hacienda castellana se encargaría de demostrar el escaso recorrido de este intento por evitar una situación que, sin duda, preludiaba una de las características más notables de mundo de las finanzas públicas, esto es, buscar rentas, arbitrios o ingresos de cualquier naturaleza sobre los cuales asentar las peticiones constantes, cotidianas y como parte del sistema que comenzaban a caracterizar el régimen de financiación de la corona. Al año siguiente, en cambio, las cuentas generales -teóricas- volvieron a moverse en ese delicado equilibrio que caracterizó a la hacienda de la Monarquía Hispánica ${ }^{47}$.

\section{Reflexiones finales}

Los estudios de los últimos años sobre las finanzas de la corona de finales del siglo XV y principios de la Edad Moderna vienen demostrando el imponente papel que jugaban ya los grupos financieros a la hora de aportar crédito y posibilidades de gestión. Junto a ello, y no casualmente, apareció otra de las dinámicas que caracterizarán a la financiación monárquica desde aquellos momentos: el riesgo constante de suspensiones, atrasos o impagos ante la deuda que generaban los continuos adelantos de capital por parte de los agentes. Se ha asimilado el problema del endeudamiento a una determinada dinastía -los Austrias- cuando también esta era una realidad cotidiana para los castellanos de los momentos previos, si bien es cierto que en un grado e incidencia muy inferior a etapas posteriores. Por tanto, si la deuda es fruto del propio sistema de financiación de la corona y de los intereses urdidos en torno

45. Ibidem.

46 Carretero Zamora, J. M.: "Los servicios de Cortes y las necesidades financieras de la monarquía castellana (1500-1515)", Cuadernos de Historia Moderna y Contemporánea, nº 8 (1987), pp. 31-56, p. 38.

47 Carretero Zamora, J. M.: Gobernar es gastar. Carlos V, el servicio de las Cortes de Castilla y la deuda de la Monarquía Hispánica, 1516-1556, Madrid, Sílex, 2016, pp. 410-412. 
a ella, habrá que convenir que no respondían simplemente a una idea de "déficit" presupuestario sino, antes bien, a la estructura misma de la real hacienda, donde los gastos tenían primacía sobre los ingresos y donde, por extensión, lo importante era allegar recursos, servir al monarca y que este recompensase a sus hombres de negocio como expresión misma de su poder.

La suspensión de 1509 demostró, en suma, que el problema de la deuda era inherente a la presencia de los grupos financieros y que su gestión se convirtió en una cuestión política. La medida de febrero de este año hay que entenderla en virtud de un escenario de crisis dinástica que, como es natural, afectó a los mecanismos de adelantos y recuperación de capitales que nutrían desde hacía tiempo a las arcas de la corona. A su vez, las propias estructuras fiscales y financieras estaban en fase de transformación desde hacía varias décadas, cuando nacieron elementos tan significativos como los encabezamientos, el recurso a los juros o la presencia de un mercado financiero en los sistemas de arrendamiento y créditos bajo diversas modalidades. Todos estos elementos estaban llamados a tener una notable influencia en épocas posteriores. Al igual que las "bancarrotas", que, como hemos tenido ocasión de observar en el presente trabajo, también contaron con algún precedente en época Trastámara.

\section{APÉNDICE I}

\section{DECRETO DE SUSPENSIÓN DE LIBRANZAS}

Archivo General de Simancas, Escribanía Mayor de Rentas, leg. 120.

"Çiertos partidos del reyno. Año de 509. Carta que se dio para que no fuesen pagadas çiertas libranças que están echas este año de 509 ny açebtadas en çiertos partidos del reino

Doña Juana etc. A vos mys arrendadores e recabdadores mayores e thesoreros e reçebtores de las rentas de las alcabalas e terçias encabeçadas e arrendadas e por encabeçar e arrendar de los partidos de Burgos e Candemuño e Çerrato e Castroxeriz e Canpo[o] e de las Quatro Villas de Santander e Laredo e Castro de Hurdiarles e San Viçente de la Varquera e de la Meryndad de Rioja e de Logroño e su merindad e los lugares del Conde de Aguilar e de la villa de Aranda e Meryndad de Allendevro e Vitoria e de la villa de Miranda e su partido e salinas de Burandón deste presente año de la data desta mi carta e a vuestros fazedores e fatores e a cada vno de vos a quien esta mi carta fuere mostrada o el traslado della signado de escribano público salud e gracia. Sepades que por mis cartas de libramientos están librados en las rentas de cada vno desos dichos partidos en los arrendadores e reçebtores dellas deste dicho presente año algunas quantías de maravedís a algunas personas porque en algunos de los dichos partidos están librados más maravedís de lo que monta en los arrendamientos e encabezamientos de las rentas dellos, e sy no se declarase quales de las dichas libranças se fan de pagar e oviese determinación de los arrendadores e reçebtores de las dichas rentas quales libranças quieren pagar e quales no, no se conplirían ny pagarían las libranças que se debiesen pagar, antes los recaudadores no pagarían ningunas diciendo que no cabían, e abría muchos pleitos e dyferençias. E porque 
çesen los pleitos e contiendas fue acordado que debía mandar dar esta mi carta en la dicha razón por la qual vos mando que vos ny alguno de vos no açebteys ny pageuys ninguna ny alguna de las libranças que [en] los dichos partidos están echas fasta oy día de la data desta mi carta a ninguna ny algunas personas syn que para ello veades otra mi carta, no envargante qualesquier libramientos que vos sean mostrados e presentados, en defeto [sic] de las quales que yo por la presente suspendo saluo sy los tales libramientos son o fueren fechos para la paga de la gente de mis guardas o sy son o fueren fechas algunos escuderos de la gente de las capitanías de mys guardas de sueldo que fouieron de aver del tiempo que serbieron en las dichas capitanías en estos reygnos e no fuera dellos, porque aquellos se han de pagar syn envargo de lo contenido en esta mi carta, con aperçibimiento que lo que de otra manera açebtaredes e diéredes e pagaredes vos lo torneys a pagar otra otra vez de vuestros bienes. E las personas que tienen fechos qualquier libramientos en el dicho partido los envían ante los mys contadores mayores para que estos se mande a declarar que los paguen e se muden e se libren en otra parte como la mi merçed fuere. E porque podría ser que algunos destos partidos no oviese recabdador ny reçebtor de las rentas dellos deste dicho año a quien se notificare esta mi carta, asy por no aver ny estar nombrado los dichos reçebtores e recaudadores como por estar absentes mando que en tal caso se notifique esta carta e se dé traslado della al escriuano del conçejo de la çibdad, villa o lugar que fuere cabeza de cada uno de los dichos partidos, el qual dicho escriuano sea obligado de la notificar e mostrar al recaudador e reçebtor de las rentas dellos e a su fator al tiempo que fuere o enviare a entender, e non tocante a las dichas rentas so pena que sea a cargo e culpa del dicho escriuano de conçejo todas las costas e gastos, yntereses e menoscabos que a cabsa de no lo faser asy se recreçieren al dicho recaudador e reçebtor o a las personas que tienen libranças en los dichos partidos. E por esta my carta mando a todas e qualesquier justicias a cada uno en su jurisdiçión e a qualesquier juezes esecutores que por virtud de qualesquier juezes esecutores que por virtud de qualesquier libranmientos, açebtaçiones e obligaciones que tenían fechos por los mis [contadores] que están librados en los susodichos partidos ny por parte dellos no esecuten ny fagan esecutar en vos los dichos arrendadores e recabdadores mayores e thesoreros e reçebtores ny en vuestros fiadores e bienes que yo por la presente suspendo el efeto de todo ello. E no fagades ende al. Dada en la villa de Valladolid a 15 días del mes de febrero año del nasçimiento de nuestro saluador Ihesu Xhristo de myll e quininyentos e nueve años.

Este dicho día XV de hebrero de 509 años se dio otra tal carta para los partydos siguientes:

Campos con Palencia, Barzial de la Loma, Carrión, Saldaña, Osma, Segovia, Sepúlveda, Ávila e su Obispalía.

Este dicho día se dio otra tal carta para los partidos siguientes: Medina del Campo, Salamanca, Toro, Çamora, Astorga, Ponferrada

Con tanto que esta carta no se entienda a los II quentos que en el dicho partydo están librados para los gastos de la casa del yfante don Fernando, mi fijo ny a las 375.000 que en el dicho partydo están libradas a Gonzalo Barrento [sic] porque aquellos ha de aver el licenciado de Vargas, my thesorero, ny a los 32.833 questán librado a Miguel de Peñanegra, alguasyl, porque los dichos maravedís se han de pagar como se 
qontiene en los libramientos que dellos están dados.

Este dya se dio otra tal carta para los partydos siguientes:

Santiago, Orense, Lugo, Mondoñedo.

Este dicho dya se dio otra tal carta para los partydos siguientes:

Madrid, Ocaña e los otros lugares de la Provincia de Castilla, Baylía del Alcáçar, Salinas de Espartinas, Alcalá de Henares, Uzeda, Yepes e Lillo e La Guardia e El Romeral, Talauera, Campo de Calatrava, Çorita, Calatrava del Andalucía.

Este dicho dya se dio otra tal carta para los partydos siguientes:

Guadalajara, Seruicio e Montazgo, Salinas de Atienza, Molina, Cuenca, Marquesado [de Villena], Grana del Marquesado, Alcaraz. Con tanto que los 150.000 que en el Seruicio e Montazgo están librados a Pedro García de Atienza e otros 5.000 que le están librados en las salinas de Atienza e otros 600.000 que le están librados en el dicho partido del Marquesado de Villena para las libranzas del ospital real e monasterio de Santa Ysabel de Granada. E asymismo 50.000 que están librados en el partydo de Molina al monasterio de San Juan de los Reyes se paguen enteramente a las paresonas que los ovieren de aver conforme a las libranzas que dellos están dados syn embargo de esta dicha carta.

Este dicho dya se dio otra tal carta para los partydos siguientes:

Murçia, Segura de la Syerra, Almedina e Torrenueva.

Este dicho dya se dio otra tal carta para los partydos siguientes:

Trusillo, terçias de Plazencia, Badajoz, Yeruas de Calatraua.

Este dicho dya se dio otra tal carta para los partydos siguientes:

Rentas mayores de Córdoua, rentas menores, alfóndiga [de Córdoba], almoxarifazgo castellano, La Ranbla e Santaella, almoxarifazgo mayor de Castilla, alhóndiga de Seuilla, madera, tres rentas, diezmo del azeite, terçias del pan, terçias de maravedíes, sierras de Aroche [sic], tercias de Carmona, Éçija, Tebafurdiales, Jerez de la Frontera, Cáliz [sic], Canarias, Gibraltar. Pero mando que los 10.000 que en el partydo de Alhóndiga de Córdoua están librados al liçençiado Çervantes e otros 12.000 a Alonso Enríquez para el letrado que ha de entender en lo tocante a las rentas de la dicha çibdad de Córdoua, que aquellos se paguen conforme a los libramientos que dellos están dados syn embargo desta dicha carta. E que asymysmo se pague el 1.000.000 que en el almoxarifazgo mayor de Seuilla está librado al ynfante don Enrique e que asymismo pague las 530.000 que están libradas en el diezmo del azeite al reçeptor de la casa del ynfante don Fernando, my fijo.

Este dicho dya se dio otra tal carta para los partydos siguientes:

Llerena, Xerez de Badajoz, La Fuente del Maestre,

Este dicho dya se dio otra tal carta para los partidos siguientes:

Baeça, Úbeda, Adelantamiento de Caçorla, Andújar, Quesada, Jahén.

Este dicho dya se dio otra tal carta para los partidos siguientes: 
Alcayçería de Granada, rentas mayores, rentas menores, fagüela, fabizes, diezmos de Granada, diezmos de las Alquerías, salinas de Granada, Seda, Alpujarras alcabalas e diezmos.

Pero mando que esta mi carta no se entienda ny estienda a las libranzas que en los dichos partidos están libradas a Pedro García de Atiença para las libranças de la capilla real de Granada, ny a los 50.000 questán librados a la yglesia de Almería en la partyda de las rentas menores de Granada ny a los 140.000 questán librados al presydente e oidores de la nuestra abdiencia de la Chançillería de Granada por que aquellos se han de pagar conforme a los libramientos que dellos están dados.

Este dicho dya se dio otra tal carta para los partydos siguientes:

Málaga, alcabalas e diezmos, Alcabalas e diezmos de Baça, Guadix, Almería, Purchena". 


\section{APÉNDICE II}

EXCEPCIONES PARTICULARES AL EMBARGO GENERAL DE RENTAS

\begin{tabular}{|c|c|c|c|c|c|c|}
\hline 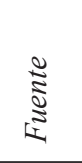 & 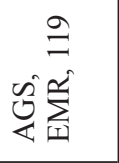 & 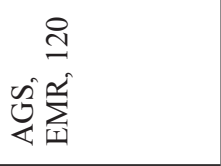 & 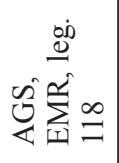 & 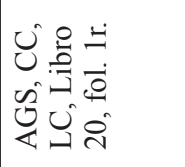 & 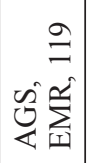 & 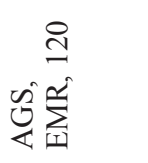 \\
\hline 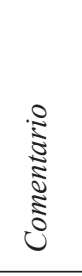 & 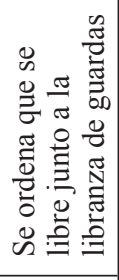 & 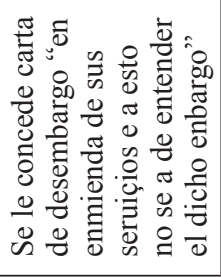 & & 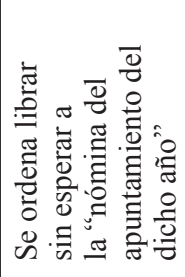 & & \\
\hline 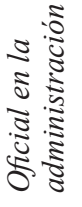 & & & 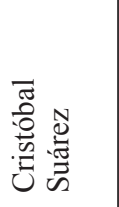 & & 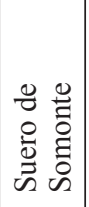 & 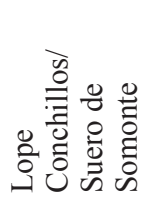 \\
\hline 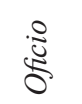 & & & & & & \\
\hline ह & 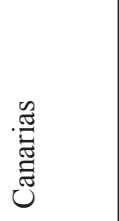 & 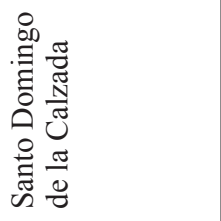 & & & 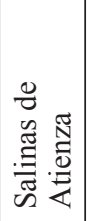 & 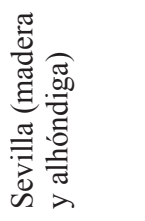 \\
\hline 遌 & 离 & 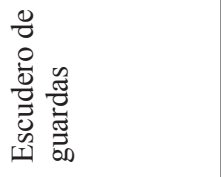 & 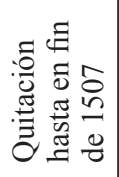 & 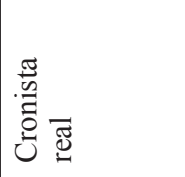 & 䳂 & \\
\hline ت & $\begin{array}{l}\text { \&े } \\
\stackrel{8}{ }\end{array}$ & $\begin{array}{l}\stackrel{8}{0} \\
\text { in }\end{array}$ & & & $\begin{array}{l}8 \\
\vdots \\
i \\
i\end{array}$ & $\begin{array}{l}\text { \&े } \\
\dot{f}\end{array}$ \\
\hline 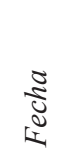 & $\begin{array}{l}8 \\
0 \\
1 \\
0 \\
1 \\
2\end{array}$ & 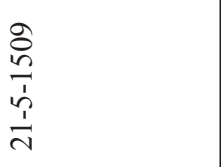 & 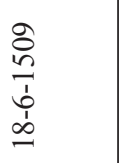 & $\begin{array}{l}\frac{8}{2} \\
\frac{1}{1} \\
\frac{1}{1} \\
\frac{1}{2}\end{array}$ & 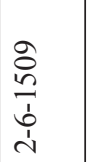 & $\begin{array}{l}\stackrel{0}{0} \\
\frac{1}{+} \\
\frac{1}{2}\end{array}$ \\
\hline ڤั & 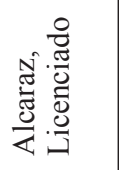 & 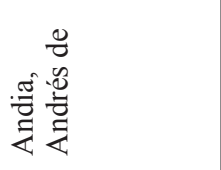 & 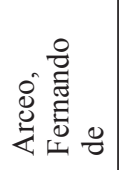 & 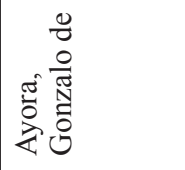 & $\begin{array}{cc}0 & 0 \\
0 & 0 \\
0 & 0 \\
0 & 0 \\
0 & 0 \\
0 & 0\end{array}$ & 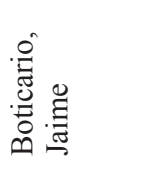 \\
\hline
\end{tabular}




\begin{tabular}{|c|c|c|c|c|c|}
\hline 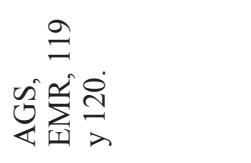 & 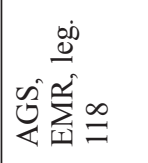 & 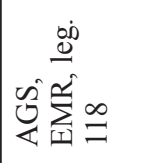 & 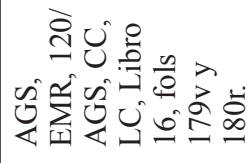 & 离 & 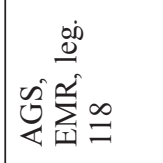 \\
\hline 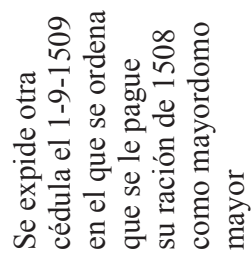 & 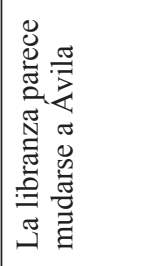 & & 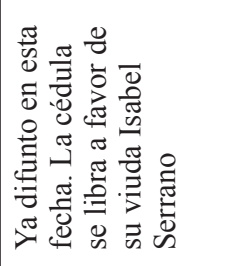 & & \\
\hline \multirow[t]{2}{*}{ 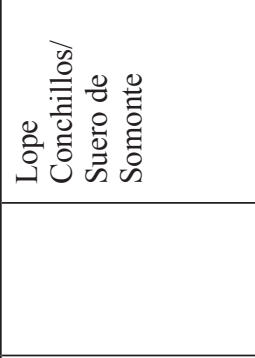 } & 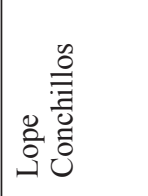 & 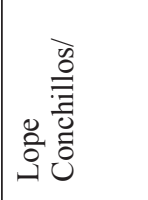 & 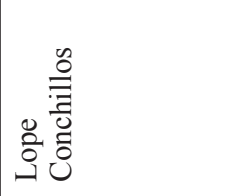 & & 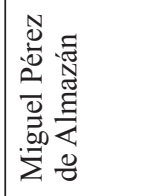 \\
\hline & 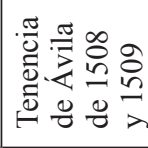 & & 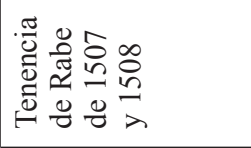 & 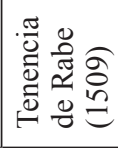 & 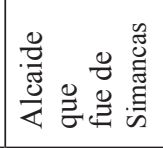 \\
\hline 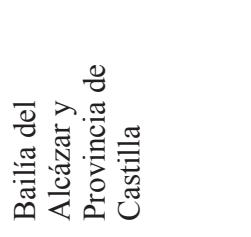 & 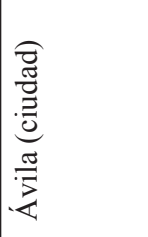 & 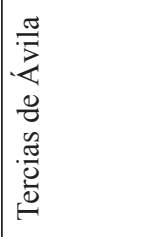 & 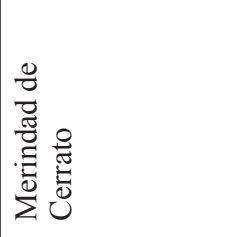 & $\begin{array}{l}\tilde{8} \\
0 \\
0 \\
0 \\
0 \\
0 \\
0 \\
0 \\
\Sigma\end{array}$ & 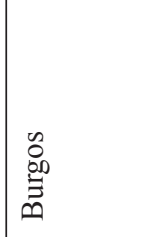 \\
\hline 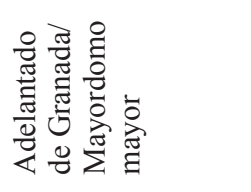 & & 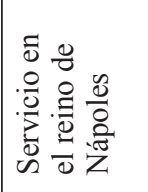 & & & \\
\hline 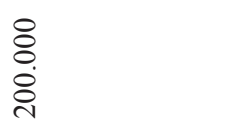 & & $\begin{array}{l}8 \\
6 \\
6 \\
0 \\
-1\end{array}$ & $\begin{array}{l}8 \\
\text { ñ } \\
\text { mi }\end{array}$ & 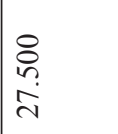 & 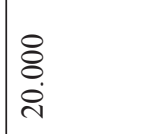 \\
\hline $\begin{array}{l}\frac{\partial}{0} \\
\frac{1}{1} \\
\text { İ } \\
\frac{1}{1}\end{array}$ & $\begin{array}{l}8 \\
0 \\
n \\
1 \\
1 \\
= \\
=\end{array}$ & $\begin{array}{l}0 \\
0 \\
n \\
0 \\
0 \\
0 \\
0 \\
-1\end{array}$ & 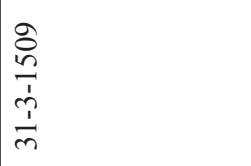 & 定 & $\begin{array}{l}2 \\
0 \\
n \\
1 \\
1 \\
0 \\
0 \\
2\end{array}$ \\
\hline 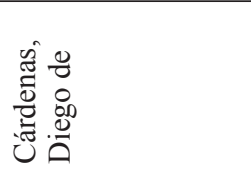 & 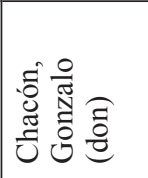 & 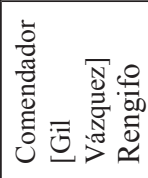 & 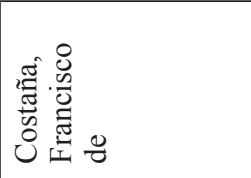 & 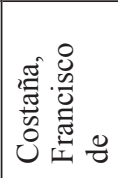 & 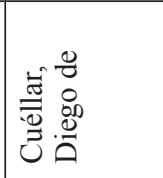 \\
\hline
\end{tabular}




\begin{tabular}{|c|c|c|c|c|c|c|}
\hline 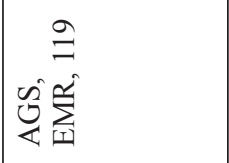 & 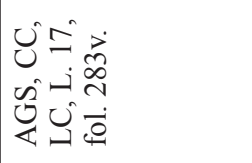 & 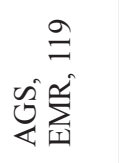 & 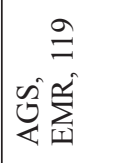 & 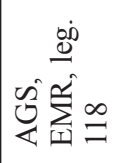 & 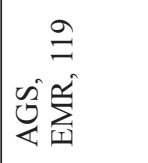 & 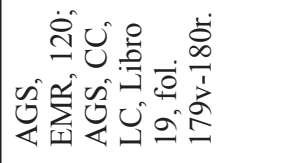 \\
\hline 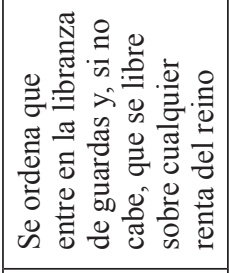 & & 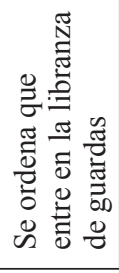 & 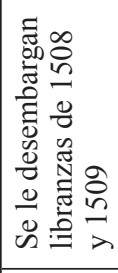 & & & 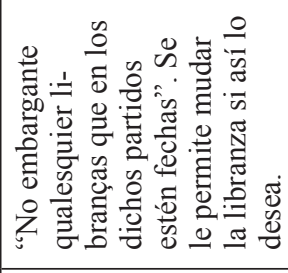 \\
\hline \multirow[t]{2}{*}{ 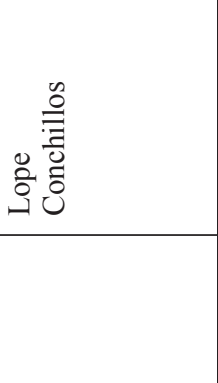 } & 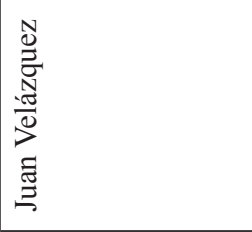 & 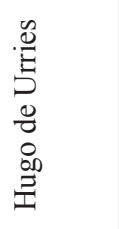 & 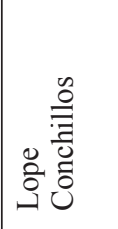 & & 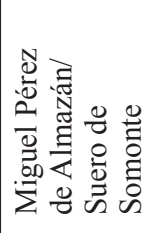 & 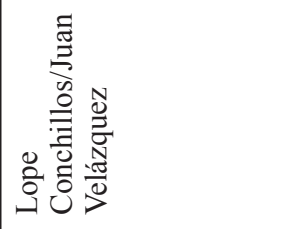 \\
\hline & 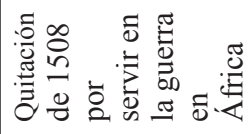 & & & 高 & & \\
\hline \multirow[t]{2}{*}{ 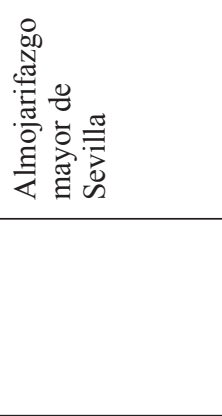 } & & 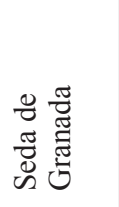 & & 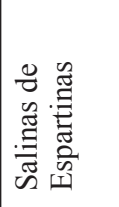 & 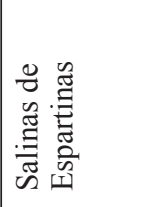 & 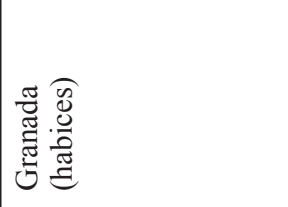 \\
\hline & 音 & 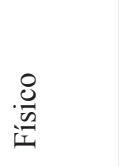 & & & 苗 & 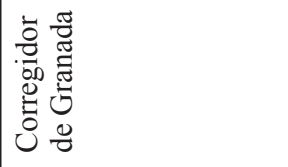 \\
\hline$\stackrel{8}{\circ}$ & & \begin{tabular}{l}
8 \\
8 \\
\hdashline
\end{tabular} & & \begin{tabular}{l}
8 \\
8 \\
\hdashline \\
$i$
\end{tabular} & $\begin{array}{l}8 \\
8 \\
0 \\
\dot{0}\end{array}$ & \\
\hline 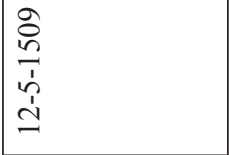 & 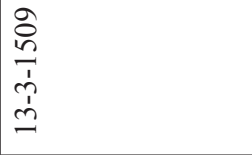 & $\begin{array}{l}8 \\
0 \\
0 \\
1 \\
0 \\
1 \\
2\end{array}$ & 总 & 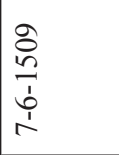 & 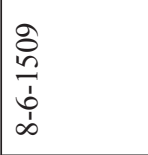 & $\begin{array}{l}2 \\
\text { in } \\
\frac{1}{1} \\
\text { ì }\end{array}$ \\
\hline 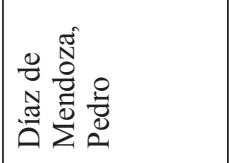 & 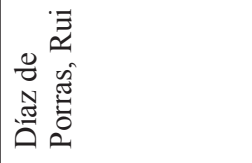 & 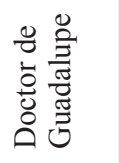 & 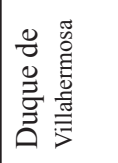 & 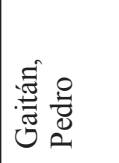 & 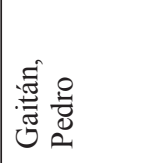 & 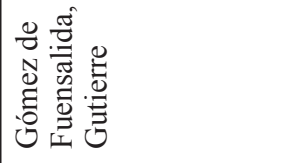 \\
\hline
\end{tabular}




\begin{tabular}{|c|c|c|c|c|}
\hline 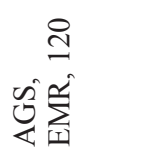 & 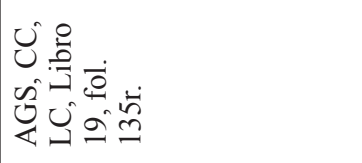 & 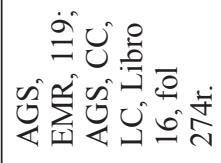 & 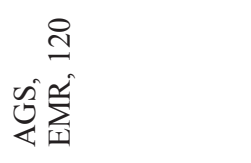 & 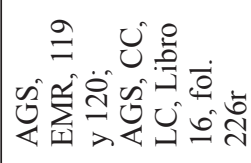 \\
\hline 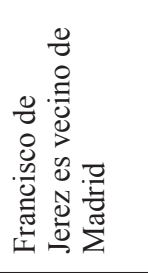 & & & 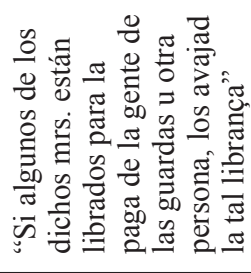 & 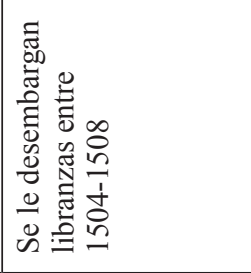 \\
\hline 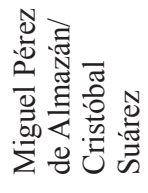 & & 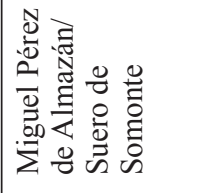 & 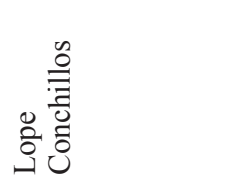 & 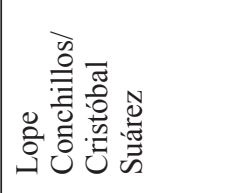 \\
\hline & 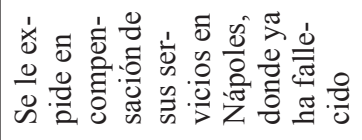 & & & 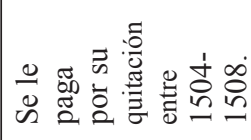 \\
\hline $\begin{array}{l}\frac{\pi}{n} \\
\frac{\pi}{\pi} \\
\sum\end{array}$ & & 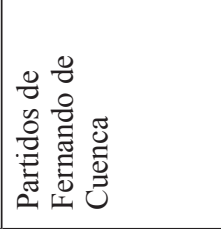 & 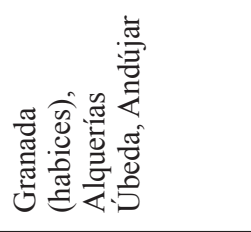 & \\
\hline 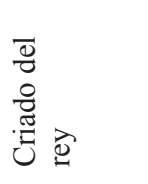 & 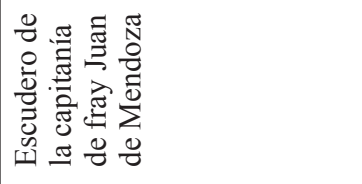 & & 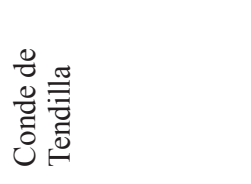 & 咅 \\
\hline \begin{tabular}{l}
8 \\
$\vdots$ \\
\hdashline
\end{tabular} & \begin{tabular}{l}
8 \\
$\vdots$ \\
\hdashline \\
2
\end{tabular} & $\begin{array}{l}8 \\
\vdots \\
\vdots \\
0 \\
0 \\
i\end{array}$ & $\begin{array}{l}m \\
\stackrel{n}{+} \\
\stackrel{i}{n}\end{array}$ & $\begin{array}{l}8 \\
8 \\
0 \\
8 \\
0 \\
0\end{array}$ \\
\hline 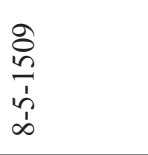 & $\begin{array}{l}\text { ते } \\
\text { ñ. } \\
\text { à่ } \\
\text { ते }\end{array}$ & 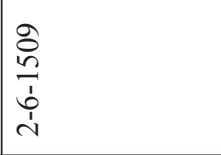 & 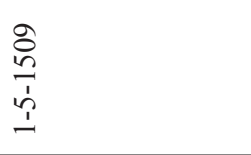 & 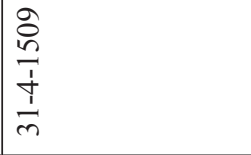 \\
\hline 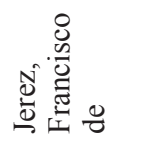 & 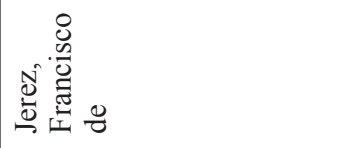 & 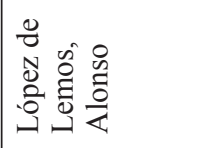 & 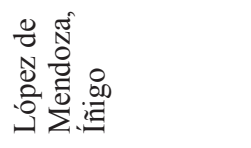 & 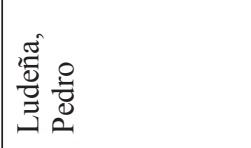 \\
\hline
\end{tabular}




\begin{tabular}{|c|c|c|c|c|}
\hline 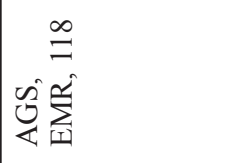 & 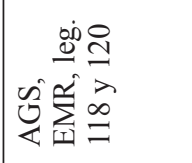 & 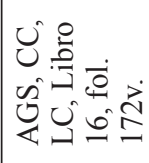 & 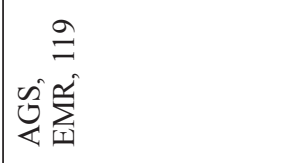 & 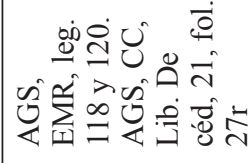 \\
\hline 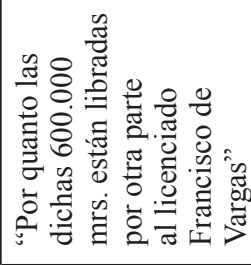 & & & 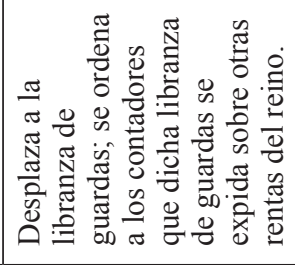 & 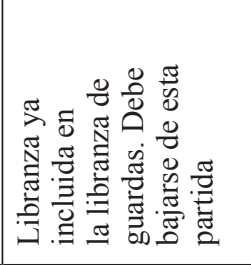 \\
\hline 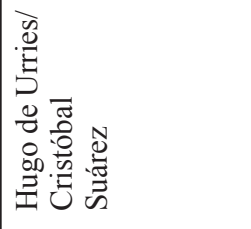 & 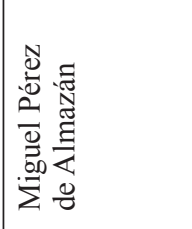 & 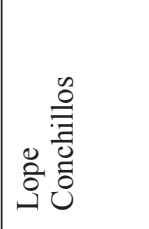 & 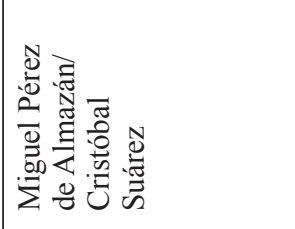 & 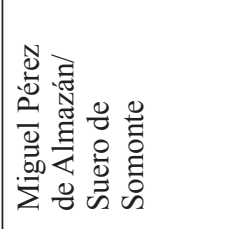 \\
\hline & 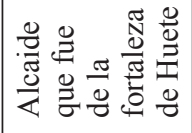 & & & \\
\hline 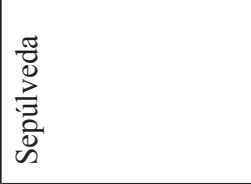 & 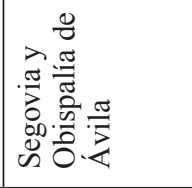 & 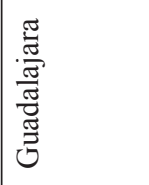 & 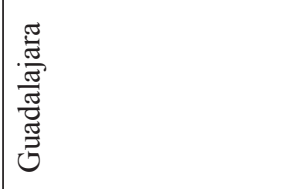 & 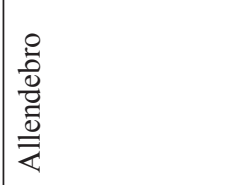 \\
\hline & & 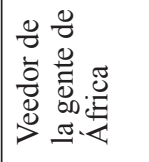 & & \\
\hline 这 & 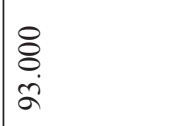 & $\begin{array}{l}8 \\
\vdots \\
\vdots \\
\text { in }\end{array}$ & $\begin{array}{l}8 \\
\vdots \\
0 \\
\grave{1}\end{array}$ & $\begin{array}{l}8 \\
0 \\
0 \\
0\end{array}$ \\
\hline $\begin{array}{l}8 \\
0 \\
n \\
1 \\
1 \\
1 \\
=\end{array}$ & $\begin{array}{l}8 \\
\text { in } \\
7 \\
\dot{1} \\
\end{array}$ & $\begin{array}{l}\text { Oे } \\
\text { h } \\
\dot{1} \\
\dot{7} \\
\text { d }\end{array}$ & 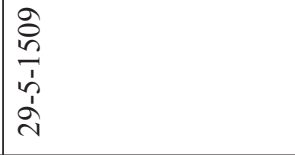 & 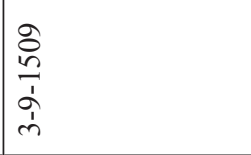 \\
\hline 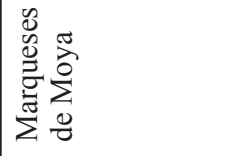 & 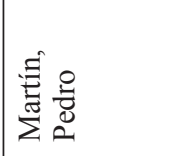 & 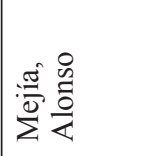 & 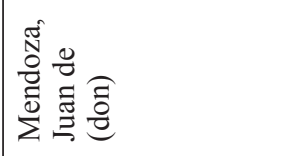 & 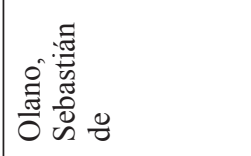 \\
\hline
\end{tabular}




\begin{tabular}{|c|c|c|c|c|}
\hline 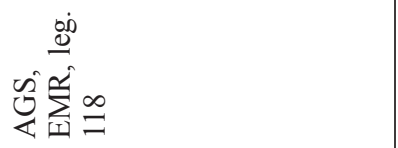 & 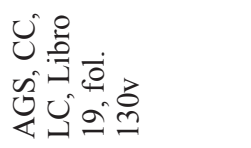 & 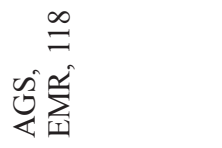 & 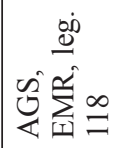 & 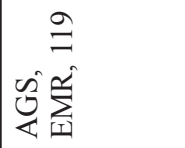 \\
\hline & & & & 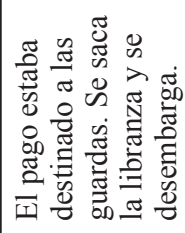 \\
\hline 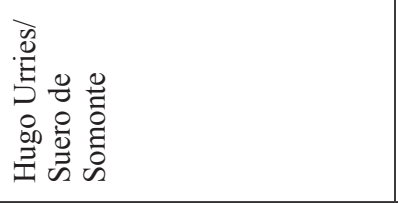 & & 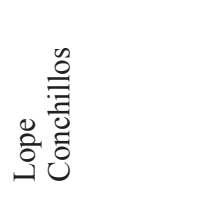 & 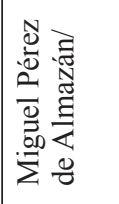 & 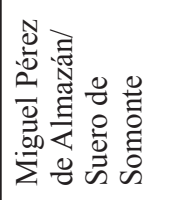 \\
\hline 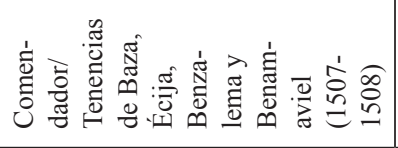 & 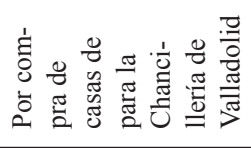 & & 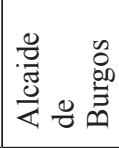 & \\
\hline \multirow[t]{3}{*}{$\begin{array}{l}\widetilde{N} \\
\mathscr{N} \\
\text { | }\end{array}$} & & & 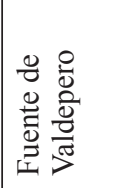 & 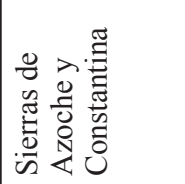 \\
\hline & 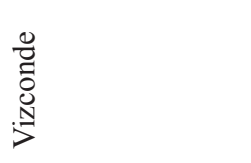 & 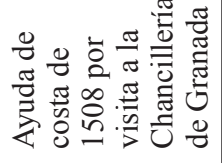 & & \\
\hline & $\begin{array}{l}\stackrel{8}{0} \\
\stackrel{\leftrightarrow}{0} \\
\stackrel{i}{i}\end{array}$ & $\begin{array}{l}\text { ¿े. } \\
\stackrel{0}{n}\end{array}$ & $\begin{array}{l}\text { \&े } \\
\dot{y} \\
\dot{q}\end{array}$ & $\begin{array}{l}8 \\
8 \\
0 \\
8 \\
\dot{q}\end{array}$ \\
\hline 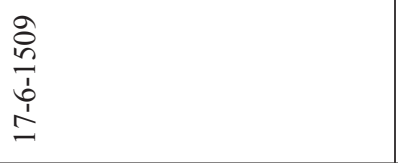 & 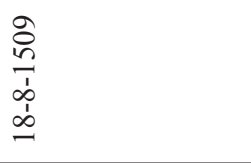 & $\begin{array}{l}\text { oे } \\
\text { ch } \\
\text { bे } \\
0\end{array}$ & 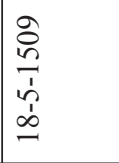 & $\begin{array}{l}o \\
0 \\
0 \\
b \\
\dot{b} \\
\dot{+}\end{array}$ \\
\hline 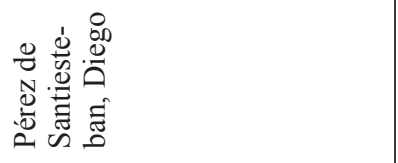 & 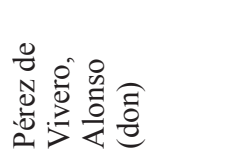 & 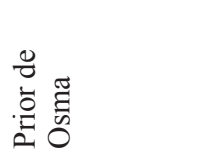 & 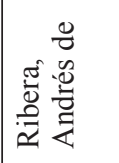 & 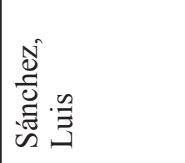 \\
\hline
\end{tabular}




\begin{tabular}{|c|c|c|c|c|}
\hline 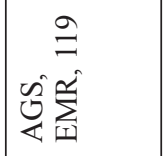 & 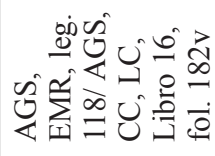 & 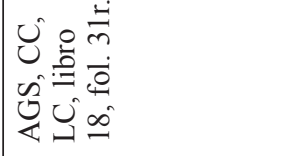 & 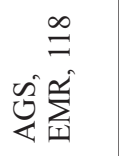 & 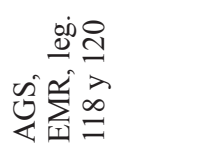 \\
\hline & & 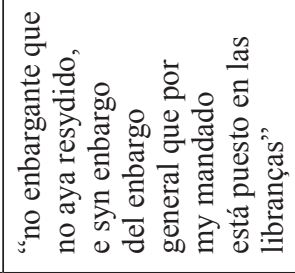 & & 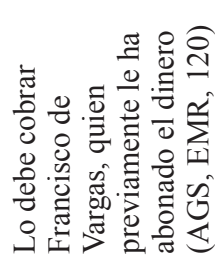 \\
\hline 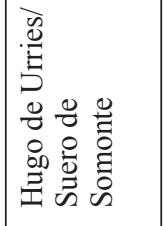 & 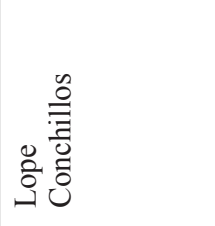 & & 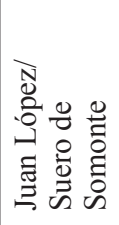 & 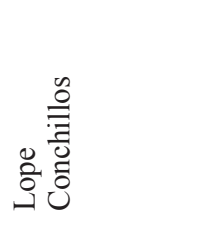 \\
\hline & 音 & 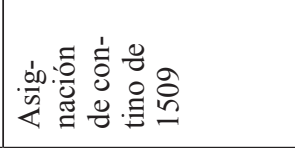 & 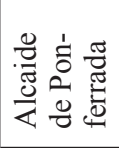 & 苞莺 \\
\hline 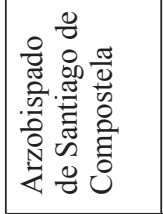 & & & 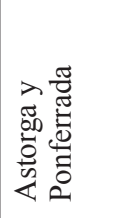 & 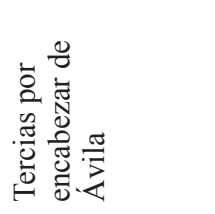 \\
\hline 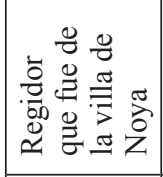 & 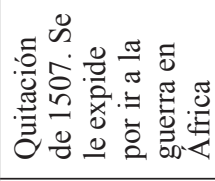 & 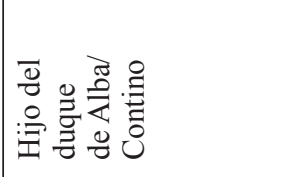 & 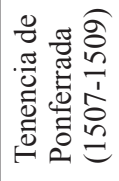 & \\
\hline $\begin{array}{l}\stackrel{\circ}{n} \\
\stackrel{n}{N}\end{array}$ & & & $\frac{8}{8}$ & $\begin{array}{l}\stackrel{0}{1} \\
i \\
\infty \\
\infty \\
m\end{array}$ \\
\hline 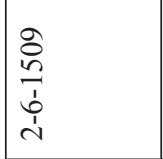 & 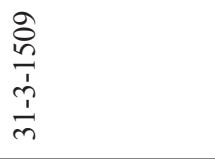 & $\begin{array}{l}\text { oे } \\
\text { in } \\
\text { à } \\
\text { àे }\end{array}$ & 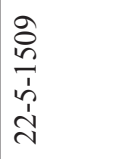 & 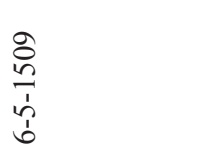 \\
\hline 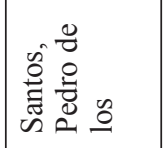 & 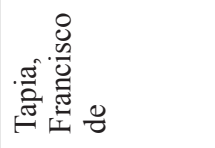 & 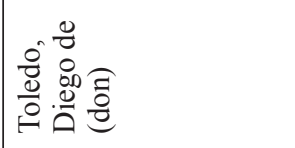 & 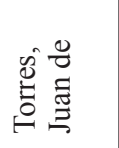 & 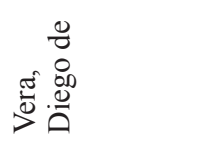 \\
\hline
\end{tabular}

